\title{
Exploring the Roles of HERC2 and the NEDD4L HECT E3 Ubiquitin Ligase Subfamily in p53 Signaling and the DNA Damage Response
}

\author{
Nicholas A. Mathieu, Rafael H. Levin and Donald E. Spratt* \\ Gustaf H. Carlson School of Chemistry and Biochemistry, Clark University, Worcester, MA, United States
}

OPEN ACCESS

Edited by:

Jean Borges Bertoldo,

Martin Luther University of

Halle-Wittenberg, Germany

Reviewed by:

Arun Upadhyay,

Northwestern University,

United States

Khosrow Rezvani,

University of South Dakota,

United States

Jason Luke Parsons,

University of Liverpool,

United Kingdom

*Correspondence:

Donald E. Spratt

dspratt@clarku.edu

Specialty section:

This article was submitted to

Cancer Molecular Targets

and Therapeutics,

a section of the journal

Frontiers in Oncology

Received: 26 January 2021 Accepted: 16 March 2021

Published: 31 March 2021

Citation:

Mathieu NA, Levin RH and Spratt DE (2021) Exploring the Roles of HERC2 and the NEDD4L HECT E3 Ubiquitin Ligase Subfamily in p53 Signaling and the DNA Damage Response.

Front. Oncol. 11:659049.

doi: 10.3389/fonc.2021.659049
Cellular homeostasis is governed by the precise expression of genes that control the translation, localization, and termination of proteins. Oftentimes, environmental and biological factors can introduce mutations into the genetic framework of cells during their growth and division, and these genetic abnormalities can result in malignant transformations caused by protein malfunction. For example, p53 is a prominent tumor suppressor protein that is capable of undergoing more than 300 posttranslational modifications (PTMs) and is involved with controlling apoptotic signaling, transcription, and the DNA damage response (DDR). In this review, we focus on the molecular mechanisms and interactions that occur between p53, the HECT E3 ubiquitin ligases WWP1, SMURF1, HECW1 and HERC2, and other oncogenic proteins in the cell to explore how irregular HECT-p53 interactions can induce tumorigenesis.

Keywords: HECT E3 ubiquitin ligases, WWP1, HERC2, HECW1, SMURF1, p53, DNA damage response

\section{INTRODUCTION}

Cell growth and division is controlled by the regulated synthesis and degradation of proteins that signal for and carry out the replication of DNA. This requires the timely expression and removal of proteins at specific checkpoints during the cell cycle to ensure proper cell division and homeostasis (1). When this delicate cellular equilibrium becomes imbalanced, unregulated cell division can occur and lead to the development of cancer. To protect against the formation of cancers, the cell has evolved an intricate network of proteins that work to recognize, target, and repair genetic abnormalities prior to its division. If significant cellular stress is recognized by these surveillance proteins, they will initiate a caspase cascade that activates lethal regulatory cell death (RCD) pathways, thereby preventing that cell from undergoing replication (2-9). Perhaps the most important protein involved in regulating these vital cellular activities is the tumor suppressor protein p53. Generally considered the "guardian of the genome", p53 is a $43.7 \mathrm{kDa}$ protein capable of undergoing more than 300 unique post translational modifications (i.e. phosphorylation (10), acetylation (11), methylation (12), SUMOylation (13), O-GlcNAcylation (14)) and interacts with a variety of proteins to dictate cellular fate following S-phase DNA duplication (15-20). One prominent PTM involved with regulating p53 activity under genotoxic and carcinogenic 
environments is ubiquitylation-a catalytic process that is carried out on p53 by select members of the homologous to E6AP C-terminus (HECT) E3 ubiquitin ligase family (21-24).

Over the past two decades, HECT-related cancer research has focused on the founding member of the HECT E3 ligase family, E6 associate protein (E6AP) (25-30). There are many studies that have cemented E6AP as a critical regulator of biochemical processes involved in the development of cervical and prostate cancer. For example, E6AP has been shown to interact with the human papilloma virus (HPV) protein E6 to target p53 for cellular degradation to produce unregulated cell division in the female cervical tissues (25). In vivo studies have also linked E6AP to metastatic forms of prostate cancer by acting to reduce tumor suppressor protein p27 expression levels in prostate gland cells $(26,30)$. Recent studies have also found that the members of the NEDD4L subfamily of the HECT E3 ubiquitin ligasesspecifically WWP1, SMURF1, and HECW1-as well as the large HECT E3 ubiquitin ligase HERC2, are linked to the pathogenesis of prostate (31), lung (32-34), colon (35-38), breast $(39,40)$, thyroid (41), gastric (42), liver (43), oral (44), and ovarian cancers $(45,46)$.

This review aims to consolidate and examine the mounting literature on how additional members of the HECT E3 ubiquitin ligase family play integral roles in regulating DNA repair and p53 cellular activities. Here we explore and summarize the specific pathways, structures, and catalytic mechanisms used by WWP1, SMURF1, HECW1 and HERC2, and how their malfunction can

\footnotetext{
Abbreviations: APC, Anaphase promoting complex; ATM, Ataxia telangiectasia mutated kinase; ATR, Ataxia telangiectasia and Rad3 related kinase; BARD1, BRCA1 associated RING domain protein 1; Bax, Bcl-2 associated X protein; Bcl2 B-cell lymphoma 2; BRCA1, Breast cancer gene 1; ChIP, Chromatin immunoprecipitation assays; $\mathrm{CPH}$, Cullin-7-PARC-HERC2 domain; Cyt-b5, Cytochrome-b5 like domain; DDR, DNA damage response; DOC, Downregulated in ovarian cancer domain; DSB, Double strand break; E1, Ubiquitin activating enzyme; E2, Ubiquitin conjugating enzyme; E3, Ubiquitin ligase; H2AX, Histone 2A family member X; HECT, Homologous to E6AP Cterminus; HECW1, HECT, C2, and WW-domain containing protein 1; HECW2, HECT, C2, and WW-domain containing protein 2; HERC, HECT and RLD containing; HERC2 - HECT and RLD containing protein 2; LATS1, Large tumor suppressor kinase 1; MAPK8, Mitogen activated protein kinase 8; MDC1, Mediator of DNA damage checkpoint 1; MDM2, Mouse double minute 2; MDMX, Mouse double minute 4 (aka MDM4); MIB, Mind bomb domain; MMP2, Matrix metallopeptidase 2; MMP9, Matrix metallopeptidase 9; MRE11, Meiotic recombination 11; NBS1, Nijmegen breakage syndrome 1; NEDD4, Neuronal precursor cell-expressed developmentally downregulated 4; NEURL4, Neuralized E3 ubiquitin protein ligase 4; p53, Tumor suppressor protein p53; PIKK, Phosphatidylinositol 3-kinase-like protein kinase; PPxY or PY, proline-rich motif; PTM, Post translational modification; RAD50, Radiation sensitive protein 50; RAP80, Receptor associated protein 80; RBR, RING-between-RING, RINGBRcat-Rcat; RCD, Regulatory cell death; RING, Really interesting new gene; RLD, Regulator of chromosome condensation 1-like domain; RNF11, RING finger protein 11; RNF8, RING finger protein 8; RUNX2, Runt-related transcription factor 2; Smad2, Mothers against decapentplegic homolog 2; Smad7, Mothers against decapentplegic homolog 7; SMURF1, SMAD ubiquitylation regulatory factor 1; SMURF2, SMAD ubiquitylation regulatory factor 2 ; TGF- $\beta$, Transforming growth factor beta; TRAIL, TNR-related apoptosis-inducing ligand; T $\beta R-I$, TGF- $\beta$ receptor I; UBE2N, Ubiquitin conjugating E2 enzyme UBE2N (aka Ubc13); WW, Tryptophan-tryptophan domain; WWP1, WWdomain containing protein 1; WWP2, WW-domain containing protein 2; ZF, Zinc finger.
}

result in oncogenesis. We also discuss developing a framework for future HECT-based cancer research that builds toward an improved overall understanding of oncogenic processes in the cell. Research on the interplay between these important protein networks will provide the necessary knowledge for developing novel treatment methods that can slow or even prevent the progression of HECT-dependent p53-related cancers.

\section{UBIQUITYLATION-A BRIEF OVERVIEW}

Ubiquitylation involves the post-translational attachment of ubiquitin, a small $8.6 \mathrm{kDa}$ protein, on to a substrate protein by an E1-E2-E3 enzymatic cascade (47-49). The human genome codes for two ubiquitin specific E1 enzymes (i.e. UBE1 and UBE1L2), 38 distinct E2 enzymes (ex. UBE2D3, UBE2L3, UBE2C, etc.) and over 1,000 unique E3 ligases (50). As ubiquitin is passed along the ubiquitylation signaling enzyme cascade (E1 to E2 to E3), the attachment of ubiquitin becomes more specific to ensure that the precise target protein is modified. This specificity from the ubiquitylation-signaling pathway can regulate various intracellular processes including protein turnover, cell cycle progression (51), apoptosis (52), cell differentiation and development (51), immune response and inflammation (53), intracellular trafficking (54), signal transduction (23), DNA transcription and repair (55), viral infection (53) and more. For the cell to carry out these processes, ubiquitin is first activated by an ubiquitin activating enzyme (E1; EC 6.2.1.45) through an ATP-dependent mechanism to form a thioester bond between the $C$-terminal carboxyl of ubiquitin and the catalytic cysteine of the E1. The ubiquitin is then transferred to an ubiquitin conjugating enzyme (E2; EC 2.3.2.23) via a trans-thiolation reaction to form a thioester bond between the $C$-terminus of ubiquitin and the conserved catalytic cysteine residue of the E2 (47, 56-58). The E2 ubiquitin complex next interacts with an ubiquitin ligase (E3) to properly coordinate the transfer of ubiquitin on to a specific lysine of the target substrate protein. Recent studies have also demonstrated that under specific cellular conditions the E3 ligases are able to catalyze the attachment of ubiquitin on to cysteine, threonine and $\mathrm{N}$-terminal methionine residues of select target proteins (59-61). While the specific function of these alternative ubiquitin substrate attachments is not fully understood and requires further examination, they do add a further dimension to the permutations that can occur with the cellular ubiquitin machinery.

There are several different classes of E3 ubiquitin ligases found in humans that include the really interesting new gene finger domain-containing (RING; EC 2.3.2.27) (62), U-box (63), RING-between-RING (RBR; also known as RING-BRcat-Rcat; EC 2.3.2.31) (64) and HECT (E.C. 2.3.2.26) E3 ubiquitin ligases. The RING E3 ubiquitin ligases are the largest and most widely studied family of E3 ligases with over 600 members identified in the human genome (65). During ubiquitylation, these enzymes act as protein scaffolds that orient the E2 ubiquitin thiolester complex and target substrate to allow for efficient ubiquitin 
transfer $(62,66)$. In contrast, the RBRs catalyze substrate ubiquitylation by using a RING-like mechanism to coordinate an ubiquitin charged E2 cognate enzyme, followed by the formation of a HECT-like thiolester intermediate between ubiquitin and the enzyme's Rcat domain to complete the ubiquitin cargo transfer onto the substrate (64, 67-69). Lastly, the HECT E3 ubiquitin ligases play a catalytic role in the final attachment of ubiquitin by forming a thiolester intermediate with its conserved catalytic cysteine prior to transferring the ubiquitin to a substrate protein (70-74).

In the context of p53 ubiquitylation, several HECT E3 ubiquitin ligases have been shown to play a role in the final attachment of ubiquitin to p53. The specific HECT E3 ubiquitin ligase that attaches ubiquitin onto p53 decides the isopeptide linkages formed in a mono-, multi mono- or polyubiquitin chain (i.e., linear via $\mathrm{N}$-terminal M1, or K6, K11, K27, K29, K33, K48, and/ or K63) to modulate p53 activity and dictate its cellular function (47-49). For example, a K48-linked polyubiquitin chain attached to p53 signals for p53 turnover by the $26 \mathrm{~S}$ proteasome (47-49), while K63-linked polyubiquitin chains control p53 intracellular trafficking (75) and transcriptional regulation of the complex between p53 and the RING E3 ubiquitin ligase mouse double minute 2 (MDM2) (76). Recent studies have also demonstrated that the HECT E3 ubiquitin ligases SMURF1 and HERC2 can regulate the activity of p53 independent of their ubiquitylation activities (i.e., no ubiquitin transfer or chain formation) $(77,78)$.

\section{HECT E3 UBIQUITIN LIGASES- IMPORTANT ENZYMES IN ONCOGENESIS}

The HECT E3 ubiquitin ligase family is comprised of 28 enzymes that contain a characteristic $\sim 350$ residue catalytic HECT domain found near their $C$-termini $(70,79,80)$. The HECT domain is bilobal, where the $N$-lobe ( $\sim 250$ residues) is responsible for recruiting and binding the E2 ubiquitin complex, while the $C$-lobe contains the absolutely conserved catalytic cysteine responsible for the ubiquitin transfer onto a target substrate $(81,82)$. Structures of the isolated HECT domains from different HECT family members have revealed unique conformational orientations for the $C$-lobe, with some showing the $C$-lobe in close proximity to the $N$-lobe while others showing a large distance of separation. These findings suggest that a flexible linker exists between the $N$-lobe and $C$-lobe of the HECT domain that allows for the free rotation of the $C$-lobe for accepting ubiquitin from the $\mathrm{E} 2$ and subsequently transferring it to a target substrate.

Apart from the highly conserved HECT domain, there is remarkable diversity in the protein-protein interaction domains found at the $N$-termini of members in the HECT family. Through the biochemical and structural distinction of these $N$-terminal domains, the family of 28 enzymes has been classified into three different HECT subfamilies i) neuronal precursor cell-expressed developmentally downregulated 4 (NEDD4), ii) HECT and RLD containing (HERC), and iii) "Other" (70, 83). Focusing specifically on the NEDD4 subfamily, each of the nine members have been shown to contain an $\mathrm{N}$-terminal $\mathrm{C} 2$ calcium binding domain involved with binding phospholipids through a calcium dependent mechanism (84), and two, three or four tryptophantryptophan (WW) domains involved in recognition of substrates with proline-rich motifs (i.e., PPxY or PY) (85) (Figure 1). Additionally, NEDD4 family members HECT, C2 and WWdomain containing protein 1 (HECW1) and HECW2 contain a unique HECW1/2 N-terminal domain thought to be involved in substrate recognition but has yet to be documented in the literature. Another HECT E3 ubiquitin ligase member belonging to the HERC subfamily, HECT and RLD containing protein 2 (HERC2), illustrates the vast diversity in $N$-terminal interaction domains (Figure 1). The HERC2 $N$-terminal protein-protein interaction domains include three regulator of chromosome condensation 1like domains (RLDs) that are suggested to be involved in chromatin binding, centrosome assembly and guanine nucleotide exchange $(101,102)$, a zinc finger (ZF) domain that is required for protein/ DNA binding (103), a unique Cullin-7-PARC-HERC2 (CPH) domain predicted to be involved in binding to tetramerized p53 $(104,105)$, and a cytochrome-b5 like domain (cyt-b5) that binds to heme and acts as a redox potential interaction domain with electron transport like properties (106). HERC2 also contains a mind bomb (MIB) domain that is thought to be involved in regulating the Notch signaling pathway to ensure proper intercellular communication during embryonic stem cell differentiation (107) and a downregulated in ovarian cancer (DOC) domain, which is similar to the anaphase promoting complex (APC) and may have a role in in the ubiquitylation activity of HERC2 (108).

The variability at the $\mathrm{N}$-terminal protein-protein interaction domains in members of the NEDD4 subfamily and HERC2 suggest that these enzymes bind and recognize a broad range of substrate proteins in the context of oncogenesis (70) (Table 1). For example, it has been shown that HECW1 (aka NEDL1), SMAD ubiquitylation regulatory factor 1 (SMURF1), WW-domain containing protein 1 (WWP1) and HERC2 each carryout unique interactions with $\mathrm{p} 53$ that involve either the direct K63 ubiquitylation of p53, as in the case of WWP1 (75) (89), and/or the formation of multiprotein enzymatic complexes that act to modulate p53 activity independent from HECT-dependent ubiquitylation (149). Collectively, these HECT-dependent interactions have been identified as critical regulators of p53 activity that impact apoptotic signaling (149), the transcription of p53 related genes (75), equilibrium of the MDM2-p53 feedback loop $(105,150)$, ataxia telangiectasia mutated (ATM) and ataxia telangiectasia and $\operatorname{Rad} 3$ related (ATR) dependent DNA double strand break responses (151), and other oncological-related cellular responses.

\section{THE NEDD4 HECT E3 UBIQUITIN LIGASES PLAY DIVERSE ROLES IN P53 MODULATION}

The NEDD4 subfamily has become increasingly important in the field of oncology, as various members have been found to upregulate and interact with important tumor suppressor network proteins such as p53. Here we describe how WWP1, HECW1 and SMURF1 regulate p53-dependent cellular functions. 


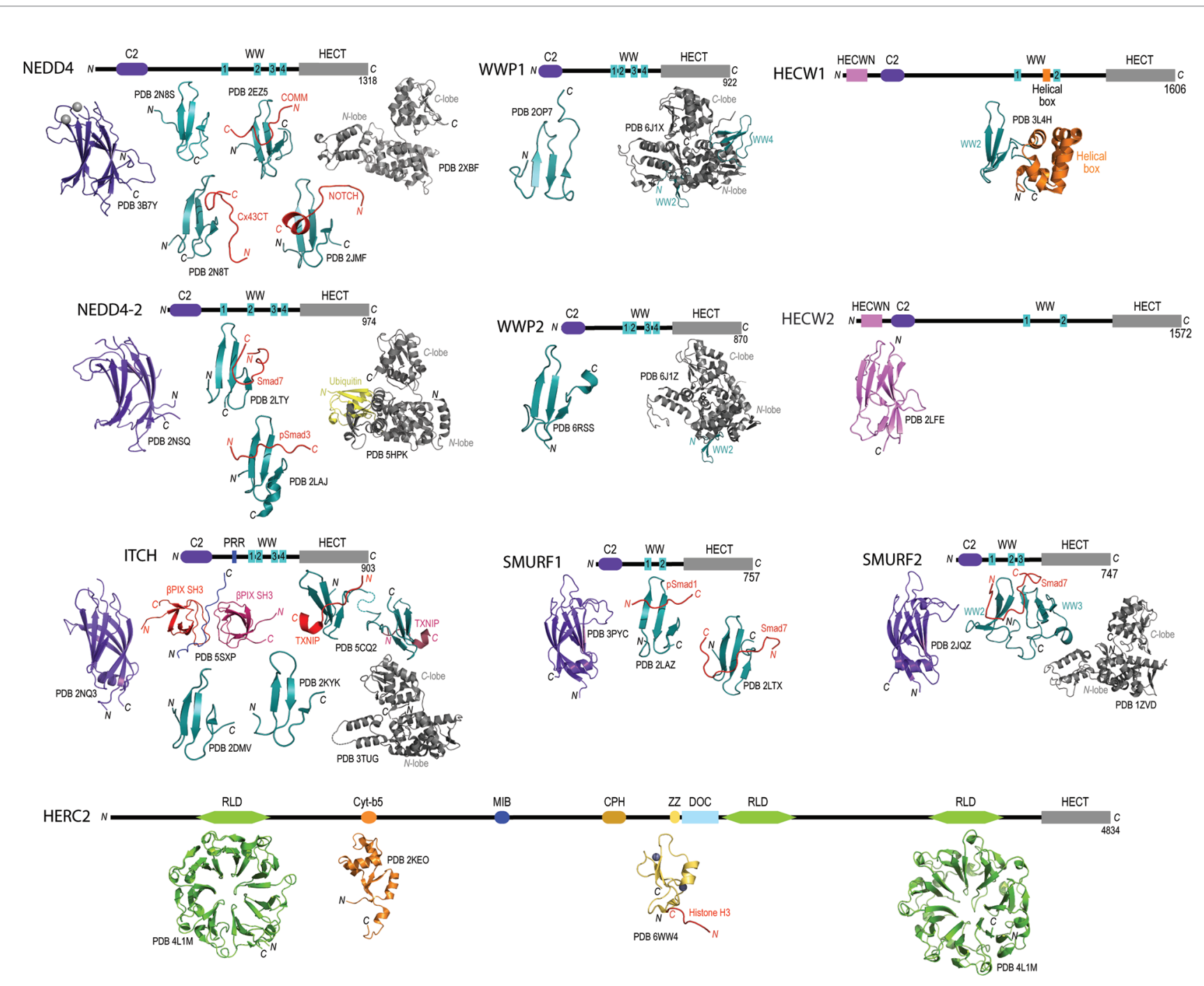

FIGURE 1 | Domain architecture and catalogue of three-dimensional structures of domains for members for the NEDD4L subfamily and HERC2. Domain architecture schematics are based upon annotated boundaries on Uniprot. All of the published or publicly available 3D structures were visualized using PyMol. NEDD4 - C2 domain bound to calcium (purple and silver spheres; PDB 3B7Y), WW domain 1 (PDB 2N8S) (86), WW domain 2 (cyan) in complex with phosphorylated Cx43CT (red; PBD 2N8T) (86), WW domain 3 (cyan) in complex with COMM (red; PDB 2EZ5) (87), WW domain 4 (cyan) in complex with NOTCH (red; PDB 2JMF) (88), and HECT domain (grey; PDB 2XBF) (89). NEDD4-2 - C2 domain (purple; PDB 2NSQ), WW domain 2 (cyan) in complex with Smad7 (red; PDB 2LTY) (90), WW domain 3 in complex with phosphorylated Smad3 (PDB 2LAJ) (91) HECT domain in complex with ubiquitin (PDB 5HPK) (92). ITCH - C2 domain (purple; PDB 2NQ3), proline-rich region (green) with $\beta$ Pix SH3 domains (reds; PDB 5SXP) (93), WW domain 1 (cyan; PDB 2DMV), WW domain 2 (cyan; PDB 2KYK), WW domains 3 and 4 (cyan) in complex with TXNIP peptide (red; PDB 5CQ2) (94), and HECT domain (grey; PDB 3TUG). WWP1 - WW domain 4 (cyan; PDB 2OP7), and WW domains 2, 3 and 4 (cyan) with HECT domain (grey; PDB 6J1X) (95). WWP2 - WW domain 4 (cyan; PDB 6RSS) (96), and WW domains 2, 3 and 4 (cyan) with HECT domain (grey; PDB 6J1Z) (95). SMURF1 - C2 domain (purple; PDB 3PYC), WW domain 1 (cyan) in complex with phosphorylated Smad1 (red; PDB 2LAZ) (91), and WW domain 2 (cyan) in complex with Smad7 (red; PDB 2LTX) (90). SMURF2 - C2 domain (purple; PDB 2JQZ) (97), WW domains 2 and 3 (cyan) in complex with Smad7 (red; PDB 2KXQ) (98), and HECT domain (grey; PDB 1ZVD) (99). HECW1 - Helical box (orange) with WW domain 2 (cyan; PDB 3L4H). HECW2 - HECWN domain (pink; PDB 2LFE). HERC2 - RLD domain 1 (green; PDB 4L1M), Cyt-b5 domain (orange; PDB 2KEO), ZZ domain bound to zinc ions (purple and grey spheres) in complex with Histone H3 tail (red; PDB 6WW4) (100), RLD domain 3 (green; PDB 3KCI).

\section{WWP1 Facilitates p53 Aggregation in the Cytoplasm in Response to p53 Overexpression}

WWP1 is a member of the NEDD4 subfamily that has been linked to colon, breast and oral cancers $(31,35,39,44,152)$. WWP1 contains two WW domains that have been shown to recruit and modulate the activity of cancer related proteins like
Runt-related transcription factor 2 (RUNX2) (153, 154), RING finger protein 11 (RNF11) $(155,156)$ and large tumor suppressor kinase 1 (LATS1) (157) via their proline-rich (PY) motifs (Figure 1). In addition to the interplay that occurs between WWP1 and these cancer-associated proteins, the enzyme can also interact with and regulate the activity of p53. Although p53 does contain a PY motif in its sequence (aa 68-91), WWP1 was 
TABLE 1 | Examples of experimentally observed protein-protein interaction of oncogenic proteins with HECT E3 ubiquitin ligases.

\begin{tabular}{|c|c|c|c|c|}
\hline Oncogenic Protein & $\begin{array}{c}\text { HECT E3 ubiquitin } \\
\text { ligase }\end{array}$ & Experimental detection method & $\begin{array}{l}\text { Region of } \\
\text { interaction }\end{array}$ & References \\
\hline $\begin{array}{l}\text { Cellular tumor antigen p53 } \\
\text { (p53, TP53) }\end{array}$ & $\begin{array}{l}\text { E6AP } \\
\text { HECW1 } \\
\text { WWP1 } \\
\text { HERC2 }\end{array}$ & $\begin{array}{l}2 \mathrm{H}, 3 \mathrm{H}, \mathrm{CE}, \mathrm{CL}, \mathrm{IF}, \mathrm{IP}, \mathrm{ITC}, \mathrm{MS}, \mathrm{PD}, \mathrm{SPR}, \mathrm{UbA} \text {, } \\
\text { X-ray } \\
\mathrm{IP} \\
\mathrm{IP}, \mathrm{PD}, \mathrm{UbA} \\
\mathrm{IP}, \mathrm{PD}\end{array}$ & $\begin{array}{l}280-781 \text { aa } \\
\text { CPH }(2547-2640 \\
\text { aa) }\end{array}$ & $\begin{array}{l}(71,79,109- \\
130) \\
(77) \\
(75) \\
(105)\end{array}$ \\
\hline $\begin{array}{l}\text { Cellular tumor antigen p63 } \\
\text { (p63, TP63) }\end{array}$ & $\begin{array}{l}\text { WWP1 } \\
\text { ITCH } \\
\text { NEDD4 }\end{array}$ & $\begin{array}{l}\mathrm{IP}, \mathrm{UbA} \\
\mathrm{IF}, \mathrm{IP}, \mathrm{NMR} \\
2 \mathrm{H}, \mathrm{IP}, \mathrm{UbA}\end{array}$ & WW domains $1 \& 2$ & $\begin{array}{c}(131) \\
(132-136) \\
(137)\end{array}$ \\
\hline $\begin{array}{l}\text { Cellular tumor antigen p73 } \\
\text { (p73, TP73) }\end{array}$ & $\begin{array}{l}\mathrm{HECW} 2 \\
\mathrm{ITCH}\end{array}$ & $\begin{array}{l}\text { IP, PD, UbA } \\
\text { IP, TAP, UbA }\end{array}$ & WW domains $1 \& 2$ & $\begin{array}{l}(138) \\
(139)\end{array}$ \\
\hline $\begin{array}{l}\text { Apoptosis-stimulating of p53 protein } 2 \\
\text { (TP53BP2) }\end{array}$ & $\begin{array}{l}\text { E6AP } \\
\text { ITCH }\end{array}$ & $\begin{array}{l}2 \mathrm{H}, 3 \mathrm{H}, \mathrm{IP} \\
\mathrm{IF}, \mathrm{IP}, \mathrm{MS}, \mathrm{PD}, \mathrm{TAP}\end{array}$ & WW domains 1-4 & $\begin{array}{c}(115) \\
(140,141)\end{array}$ \\
\hline Melanoma-associated antigen 12 (MAGE12) & E6AP & $2 \mathrm{H}, 3 \mathrm{H}$ & & $(115)$ \\
\hline $\begin{array}{l}\text { Promyelocytic leukemia protein } \\
\text { (PML, MYL TRIM19) }\end{array}$ & E6AP & $\mathrm{IF}, \mathrm{IP}, \mathrm{UbA}$ & & $(142)$ \\
\hline Mouse double minute 2 homolog (MDM2) & NEDD4 & MS, PD, UbA & & $(143)$ \\
\hline $\begin{array}{l}\text { Breast cancer type } 1 \text { susceptibility protein } \\
\text { (BRCA1) }\end{array}$ & HERC2 & $\mathrm{IP}, \mathrm{MS}, \mathrm{UbA}$ & $\begin{array}{l}\text { HECT domain } \\
\text { (4252-4834 aa) }\end{array}$ & $(144)$ \\
\hline BCL-2-antagonist/killer (BAK) & HERC1 & IF, PLISA & $\mathrm{BH} 3$ domain & $(145)$ \\
\hline Large tumor suppressor 1 (LATS1) & $\mathrm{ITCH}$ & $\mathrm{IP}, \mathrm{MS}, \mathrm{PD}, \mathrm{UbA}$ & WW domains 1-4 & $(146,147)$ \\
\hline Protein Kinase B (AKT) & $\mathrm{ITCH}$ & MS & $\begin{array}{l}\text { Phosphorylation } \\
\text { @ S257 }\end{array}$ & $(148)$ \\
\hline
\end{tabular}

Detection methods: $2 H$, yeast or mammalian-two hybrid; $3 H$, yeast or mammalian-three hybrid; CE, co-elution during chromatography purification; CL, chemical crosslinking; IF, immunofluorescence; IP, immunoprecipitation; ITC, isothermal titration calorimetry; MS, liquid chromatography or MALDI MS/MS; NMR, nuclear magnetic resonance; PD, pulldown using GST, His or MBP tag; PLISA, proximity ligation in situ assay; SPR, surface plasmon resonance; TAP, tandem affinity purification; UbA, ubiquitylation assay; X-ray, X-ray crystallography. Given the HECT family's diverse regulation of $p 53$ coupled with the well-established role of p53 in maintaining proper cell division and DNA integrity, members of the HECT E3 ubiquitin ligase family are promising oncological drug targets where their structural and mechanistic interactions with p53 can potentially be directed to modulate p53 activity and elicit precise HECT-p53 dependent anti-cancer cellular responses.

observed to bind to p53's DNA binding domain and not with its WW domains (Figure 2). Intriguingly, this association was abolished when the PY motif of p53 was deleted, suggesting that the conformation $\mathrm{p} 53$ adopts in the presence of its PY motif is required for proper WWP1-p53 complex formation (75). This unusual interaction was also found to increase the stability of p53, in contrast to the destructive effects mediated by binding of other ubiquitin ligases such as the RING E3 ubiquitin ligase MDM2 (158). The ubiquitylation activity of WWP1 was required for p53 stabilization, as an inactive version of WWP1 with its catalytic cysteine substituted with an alanine reduced p53 stability in a dominant negative fashion (75). Surprisingly, the WWP1-dependent stability of p53 was inversely proportional to the transcriptional activities of $\mathrm{p} 53$, which can attributed to the WWP1-p53 complex translocation from the nucleus to the cytoplasm and its subsequent aggregation (75).

The observation that WWP1 interacts with p53 suggests that WWP1 might be involved in tumor suppressor networks. For example, WWP1 silencing in two osteosarcoma cell lines promoted apoptosis and reduced cell invasion (159). This suppression also resulted in decreased expression of B-cell lymphoma 2 ( $\mathrm{Bcl} 2)$, matrix metallopeptidase 2 (MMP2), matrix metallopeptidase 9 (MMP9) and $\beta$-catenin, while proapoptotic proteins $\mathrm{Bcl}-2$ associated $\mathrm{X}$ protein (Bax) and $\mathrm{E}$ cadherin expression levels increased indicating that WWP1 may play a role in pro-apoptotic pathways (159). Studies have also demonstrated that WWP1 contributes to extrinsic apoptosis. For instance, the inhibition of WWP1 correlated with elevated levels of apoptosis initiator caspases 8 and 9, mitogen activated protein kinase 8 (MAPK8), as well as executioner caspase 7 via the TNR-related apoptosis-inducing ligand (TRAIL) death receptor (160). This change in phenotype was shown to be reversible with the overexpression of wild-type WWP1 but could not be rescued with an inactive version of the protein (160). Taken together, these results show that the ubiquitylation activity of WWP1 is required to inhibit apoptosis and promote the progression of particular colon and thyroidal cancers.

Studies have also demonstrated that WWP1 is involved in prostate cancer. For example, WWP1 overexpression caused by chromosomal duplication events was observed in prostate xenografts (31). Knockout studies also revealed that the loss of WWP1 resulted in increased transforming growth factor beta (TGF- $\beta$ ) receptor 1 (T $\beta \mathrm{R}-\mathrm{I})$ and mothers against decapentaplegic homolog $2(\operatorname{Smad} 2)$ protein levels, which in turn enhanced the inhibitory effect of TGF- $\beta$ (31). These results are consistent with previous studies highlighting the role of WWP1 as a negative regulator of TGF- $\beta$. In this regulatory pathway, WWP1 binds to Smad7 via a WW/PY interaction, independent of its ubiquitylation activity (161). This binding and regulation of Smad7 has also been observed with other members of the NEDD4 family (i.e. SMURF1 and SMURF2) (162-165). Co-immunoprecipitation experiments revealed that Smad7, WWP1 and T $\beta$ R-I are in close proximity within the cell and 


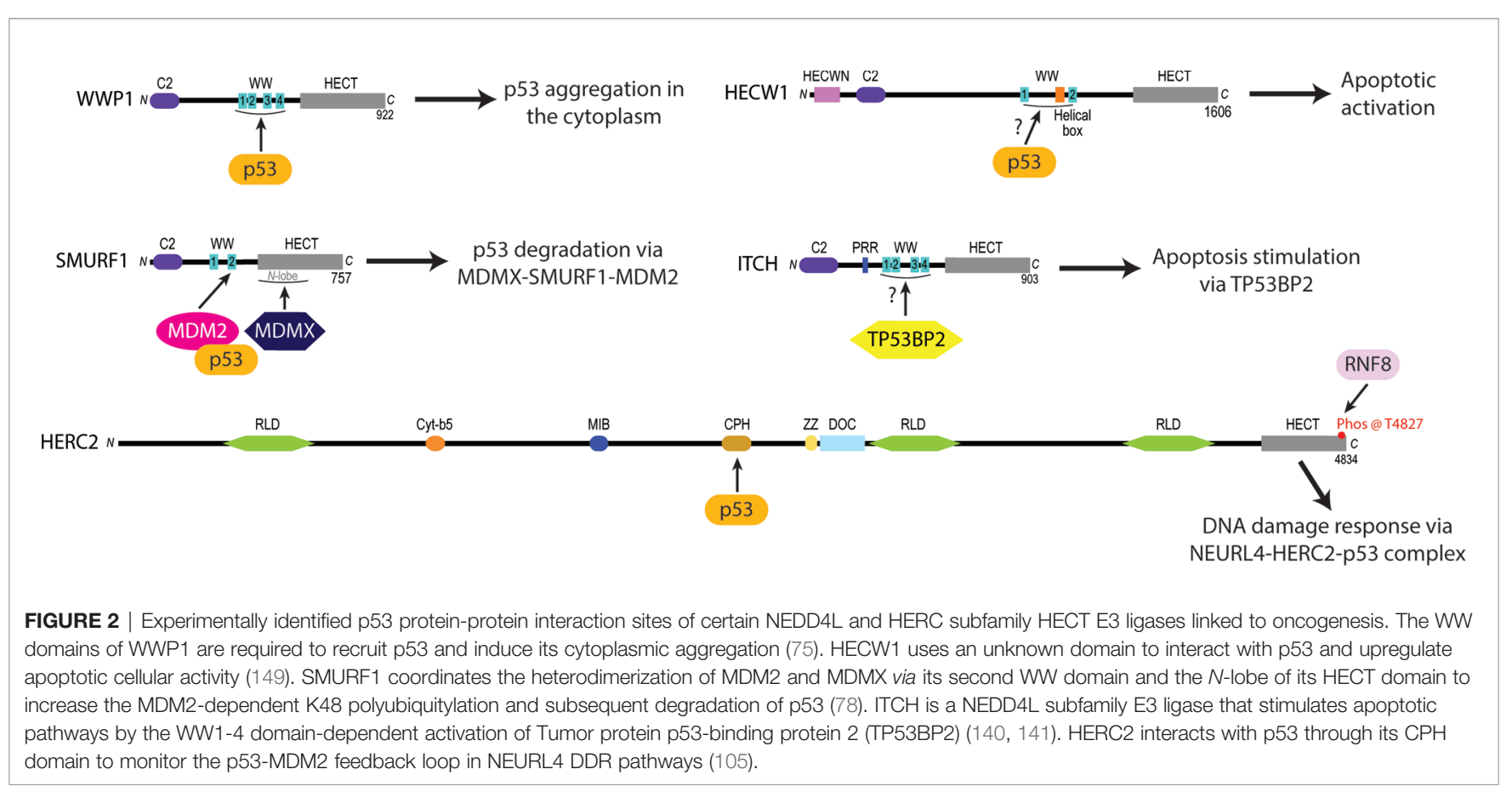

may form a complex that allows for WWP1 to ubiquitylate T $\beta \mathrm{R}-1$ and target it for proteasomal degradation (161).

These cumulative studies demonstrate that WWP1 is an important enzyme in the regulation p53 mediated gene transcription and apoptosis. With research that implicates WWP1 in prostate and osteosarcoma, it is critical that additional studies be conducted to investigate possibilities of modulating the activity of WWP1 to elicit specific anti-cancer responses in the cell. For example, by using structural techniques to determine how 553 is bound and stabilized by an active form of WWP1 in the cytoplasm, it will become possible to elucidate the biochemical and biophysical properties of the WWP1-p53 complex as well as the mechanism of ubiquitin transfer. This newfound knowledge will aid in the design of artificial molecular machinery that acts to repress WWP1 interactions with p53 and hence regain normal p53 anti-tumor activity in active cancer cells. Additionally, by expanding our knowledge of other important WWP1-substrate interactions, including the recognition and binding of WWP1 to TGF- $\beta$ receptors, the successful elucidation and categorization of the WWP1 interactome can be achieved to provide a clearer map of the pathological role(s) of WWP1.

\section{HECW1 Positively Regulates p53 to Induce Apoptotic Pathway Activation}

Recent biochemical studies have demonstrated that HECW1 possesses tumor suppressive activity by interacting with the $C$ terminus of p53 to upregulate the activation of p53-cisplatin dependent apoptotic cellular pathways $(77,149)$. This study also found that both the wild-type and isolated HECT constructs of HECW1 interact with p53, suggesting that the HECW1dependent pro-apoptotic activation of p53 is independent of its ubiquitylation activity (77). Additionally, chromatin immunoprecipitation assays (ChIP) have demonstrated that HECW1 directs $\mathrm{p} 53$ to the $\mathrm{p} 21$ wafi promoter region to induce the transcriptional activation of p53-related genes in response to carcinogenic cellular signals (149). There are currently no structural or mechanistic studies to explain how HECW 1 forms a complex with $\mathrm{p} 53$ to regulate apoptotic anticancer activities within the cell. Taken together, these findings demonstrate the need for new structural and interactor-based studies on HECW1 to begin elucidating the exact mechanisms used by the enzyme to catalyze the activation of p53-induced apoptosis in cancerous cell lines. It will be important to determine the specific domains that HECW1 uses to recognize p53, define the conformational changes that HECW1 and p53 undergo to modulate p53 cellular activity, and decipher how the HECW1-p53 complex signals for the upregulation of p53 apoptotic signaling. Studies are also needed to examine how the HECW1-p53 interaction directs the migration of HECW1 to the nucleus where it promotes p53 activation of apoptotic related genes. By addressing these unknowns about the interplay between HECW1 and p53 cellular interplay, we may be able to fine tune the design of small molecule drugs that stimulate, activate, and enhance the HECW1-dependent activation of p53induced apoptotic pathways in malignant cells.

\section{SMURF1-Dependent MDM2/MDMX Heterodimerization Negatively Regulates p53 Activity}

SMURF1 is another member of the NEDD4 subfamily that acts to negatively regulate p53 activity during breast (40), ovarian (46), gastric (42), and glioblastoma (166) tumorigenesis by augmenting the ubiquitylation activity of MDM2 - a RING E3 
ligase that specifically targets p53 for proteasomal degradation (76, 158, 167, 168). Previous findings have demonstrated that SMURF1 uses its WW domains to recognize and bind target substrates before carrying out their HECT-dependent ubiquitylation (169-171). Contrary to this traditional HECT E3 function, recent studies have discovered a unique function of SMURF1 whereby it promotes the cellular stability of MDM2 substrates by facilitating the heterodimerization of MDM2 and its homolog mouse double minute 4 protein (MDMX, aka MDM4) (78). The ability of SMURF1 to mediate MDM2MDMX heterodimerization is thought to rely on the coordination of MDM2 with its second WW domain while MDMX interacts with the HECT $N$-lobe of SMURF1 (78) (Figure 2). A consequence of these multiprotein interactions is the structural inhibition of the MDM2 auto degradation pathway by MDMX. Not surprisingly, this interaction has been shown to result in the prolonged stability of MDM2 in vivo with an increase in the K48-polyubiquitylation activity of MDM2 on p53 (78).

To date, MDM2 and MDMX are the only substrates known to interact with the second WW domain and HECT domain of SMURF1 and not be targeted for ubiquitylation. It remains unresolved how the unusual stabilization effects that SMURF1 provides for MDM2 and MDMX occur on the mechanistic and molecular level. Of interesting note is that MDM2 and MDMX are bound by SMURF1 at its second WW domain and HECT domain, the same enzymatic regions used by the SMURF1 to carry out the ubiquitylation of its target substrates $(76,78,158$, 167, 168). These findings make it conceivable that SMURF1 might bind MDMX in an analogous fashion to an E2 cognate enzyme at the $N$-lobe of its HECT domain. Likewise, with MDM2 bound by SMURF1 by its second WW domain, it is possible that the coordination of MDM2 to MDMX is facilitated by conformational shifts in the SMURF1 domain architecture that are similar to the mechanisms used by the SMURF1 to carry out the ubiquitylation of its target substrates.

Recent studies have determined that MDM2 and MDMX form a ternary complex with SMURF1 to promote MDM2/ MDMX heterodimerization, which subsequently can recruit p53 to the complex with MDM2 serving as the bridging molecule within the MDMX-SMURF1-MDM2-p53 multiprotein complex $(76,78)$. While the exact function of this ternary intermediate remains unclear in the context of p53 signaling, biochemical pull-down assays have shown that p53 does not associate with the MDMX-SMURF1-MDM2 heterotrimer if the $\mathrm{N}$-terminus of MDM2 is truncated (a.a. 1-76) (78), and that SMURF1 does not interact with p53 in the absence from MDM2 (78). These findings suggest that the $N$-terminus of MDM2 functions to recognize and bind p53 in addition to being the point of interaction for the second WW domain of SMURF1. It is critical that follow up structural studies be performed to examine if the $N$-terminal domain of MDM2 causes any conformational changes within the MDMX-SMURF1-MDM2 ternary complex and how these conformational changes may play a role in MDM2-MDMX heterodimerization and $\mathrm{p} 53$ regulation. Likewise, it will be important to examine how the unique structural interactions that occur between SMURF1, MDM2, and MDMX impact the ability of SMURF1 to stabilize MDM2, and how the subsequent regulation of MDM2 activity by SMURF1 plays a role in p53-dependent cancer development.

SMURF1's tight regulation of MDM2-dependent p53 ubiquitylation makes it a promising candidate for oncological drug development. An improved understanding of the mechanisms used by SMURF1 to promote MDM2-MDMX heterodimerization at the molecular level can be applied pharmacologically to regulate MDM2 p53 ubiquitylation activity in cancer cells, and therefore serve as a powerful tool to activate pro-apoptotic pathways and interrupt cell division.

\section{HERC2-A NOVEL HECT E3 UBIQUITIN LIGASE LINKED TO CANCER DEVELOPMENT}

Recent biochemical studies have identified HECT E3 ligases outside of the NEDD4 subfamily that regulate p53 activity. Here we describe how new research is beginning to reveal that HERC2 is a major player in mediating DNA repair by regulating p53 activity.

\section{HERC2 Mediates p53 Activity Through the Formation of a Multiprotein Ternary Complex in Response to DNA Damage}

HERC2 is a large $500 \mathrm{kDa}$ multidomain E3 ubiquitin ligase that interacts with neuralized E3 ubiquitin protein ligase 4 (NEURL4) and MDM2 to modulate p53-dependent gene expression during the ATM and ATR induced DNA double strand break (DSB) repair response $(105,150)$. The HERC2-dependent activation of p53 is initiated by HERC2-NEURL4 complex formation that induces an allosteric conformational shift in the unique $\mathrm{CPH}$ domain of HERC2 $(105,150)$ (Figure 3$)$. This change in conformation allows HERC2 to recruit oligomerized p53 with its $\mathrm{CPH}$ domain to form a NEURL4-HERC2-p53 ternary complex $(105,150)$. The NEURL4-HERC2-p53 complex then coordinates with the RING E3 ubiquitin ligase MDM2 that is usually responsible for targeting p53 for cytosolic trafficking via monoubiquitylation (172) and/or proteasomal degradation via K48-polyubiquitylation $(57,63,64)$ under normal cellular conditions. However, during the ATM and ATR-activated DSB repair process, HERC2 is phosphorylated at T4827 on its $C$ terminal tail by phosphatidylinositol 3-kinase-like protein kinase (PIKK) to recruit the kinases ataxia telangiectasia mutated (ATM) and ataxia telangiectasia and Rad3 related (ATR) to the higher order NEURL4-HERC2-p53 complex where they catalyze the phosphorylation of oligomerized p53 and MDM2 (105, 150, 173). Following phosphorylation, MDM2 releases itself from the complex and carries out auto-polyubiquitylation to signal for its proteasomal degradation. Simultaneously, p53 is further stabilized by the $\mathrm{CPH}$ domain of HERC2 following its ATM and ATR-mediated phosphorylation and is no longer a target of MDM2 for polyubiquitylation $(105,150)$. The activated p53 


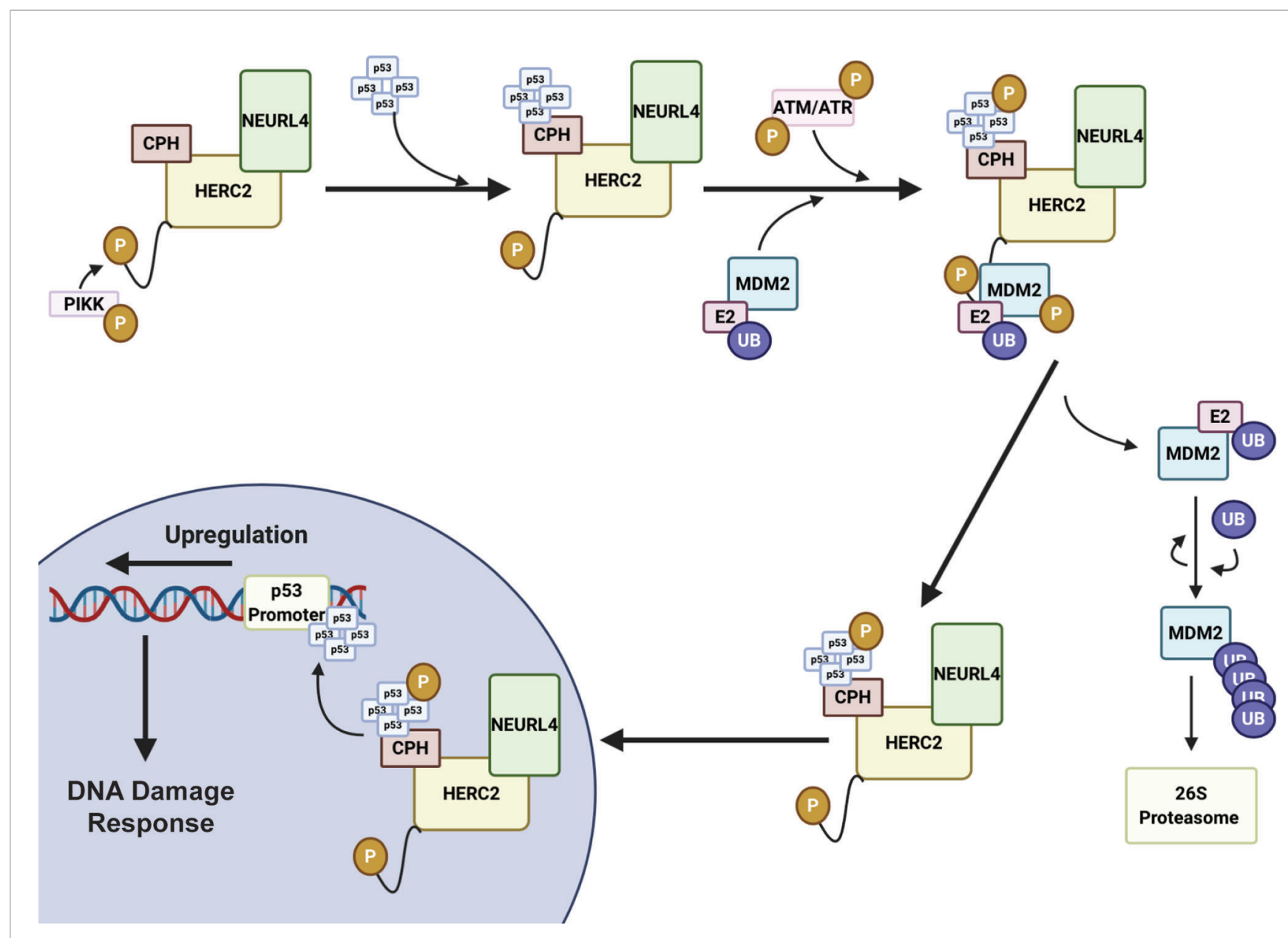

FIGURE 3 | HERC2 serves as a master regulator of p53 gene transcription in response to DNA damage. HERC2 recruits oligomerized p53 with its CPH domain to form a NEURL4-HERC2-p53 ternary complex and is phosphorylated at T4827 on its C-terminal tail by phosphatidylinositol 3-kinase-like protein kinase (PIKK). The HERC2-NEURL4-p53 ternary complex coordinates with the RING E3 ubiquitin ligase MDM2. The kinases Ataxia telangiectasia mutated (ATM) and Ataxia telangiectasia and Rad3 related (ATR) are also recruited to the multiprotein structure. ATR and ATM carry out the phosphorylation of MDM2 and oligomerized p53. Phosphorylated MDM2 becomes unstable and dissociates from the HERC2 scaffolding to allow for its K48 auto-polyubiquitylation and the cytoplasmic stability of the HERC2-NEURL4-p53 ternary complex. The HERC2-NEURL4-p53 ternary complex migrates to the nucleus where it releases oligomerized p53. p53 binds to the p53 promoter regions where it initiates the upregulation of genes to aid in cellular DNA repair and the DNA damage response. This figure was created with BioRender.com.

oligomers are then transported by the HERC2-NEURL4 complex to the nucleus and bind to p53 promoter regions where p53regulated genes including p53, p21 and MDM2 become upregulated to aid in cellular DNA repair $(105,150)$. Once the cell's DNA damage response (DDR) is complete, ATM and ATR become targets of E3 ligases for proteasomal degradation and the HERC2-NEURL4 complex coordinates the MDM2-dependent degradation of p53 (167). Taken together, HERC2 acts as a master regulator of $\mathrm{p} 53$ transcriptional activation by selectively recruiting ATM and ATR kinases to modulate MDM2 and p53 stability throughout the DDR cycle. It remains unclear what specific structural conformations and mechanisms are used by HERC2 to control p53 stabilization by ATM and ATR dependent phosphorylation, or how p53 is targeted for degradation by MDM2-dependent ubiquitylation following its recruitment by the $\mathrm{CPH}$ domain of HERC2. Future studies are needed to clarify how the unique domains of HERC2 direct the ATM and ATRdependent phosphorylation of p53 and p53-MDM2 regulation. An improved understanding of these mechanisms can potentially be exploited in novel oncological therapies that specifically target the p53-MDM2 feedback loop as a regulator of DNA replication and repair.

\section{HERC2 Is a Novel Oncogenic Suppresser That Regulates the DNA Damage Responses and Screens the Genome Prior to Replication}

In addition to regulating the MDM2-p53 transcriptional feedback loop, HERC2 can also prevent potentially oncogenic mutations from being passed into daughter cells by coordinating DNA double strand break (DSB) repair responses during the $\mathrm{S}$ and 
G2-M phases of mitosis (174-179). The HERC2-DSB repair pathway is initiated when a double strand break is sensed by the MRN complex - meiotic recombination 11 (MRE11), Nijmegen breakage syndrome 1 (NBS1), and radiation sensitive protein 50 (RAD50) (151). After recognizing the DSB, NBS1 recruits ATM kinases to the damage site where they phosphorylate Histone 2A Family Member X (H2AX) and Mediator of DNA Damage Checkpoint 1 (MDC1) (151). These phosphorylation events promote $\mathrm{H} 2 \mathrm{AX}$ and $\mathrm{MDC} 1$ complexation and signal for the recruitment of HERC2 and RNF8, a RING E3 ubiquitin ligase, to the DSB $(176,180)$. Once arriving to the damage site, HERC2's $C$-terminal tail is phosphorylated by PIKK at T4827 to promote its complexation with RING finger protein 8 (RNF8), an E3 ubiquitin ligase (Figure 4). Following RNF8 recruitment, HERC2 uses its $C$ terminal tail to stimulate the oligomerization of RNF8 and facilitates the formation of the HERC2-MDC1-RNF8 ternary complex. Phosphorylation signal cascades are used by these ternary complexes to carry out RNF8 mediated recruitment of RNF168, another RING E3 ubiquitin ligase, and its cognate E2 cognate enzyme UBE2N (aka Ubc13), to the DNA damage site (181). This multiprotein complex then works cooperatively to attach K63-polyubiquitin chains on to chromosomal histone proteins $\mathrm{H} 2 \mathrm{~A}$ and $\mathrm{H} 2 \mathrm{Ax}$. The K63 polyubiquitin linkages made on these histone sites are in close proximity to the DSB and serve as biochemical markers that recruit homologous DNA repair factors. These include breast cancer gene 1 (BRCA1), BRCA1 associated RING domain protein 1 (BARD1), receptor associated protein 80 (RAP80), and the non-homologous end joining repair

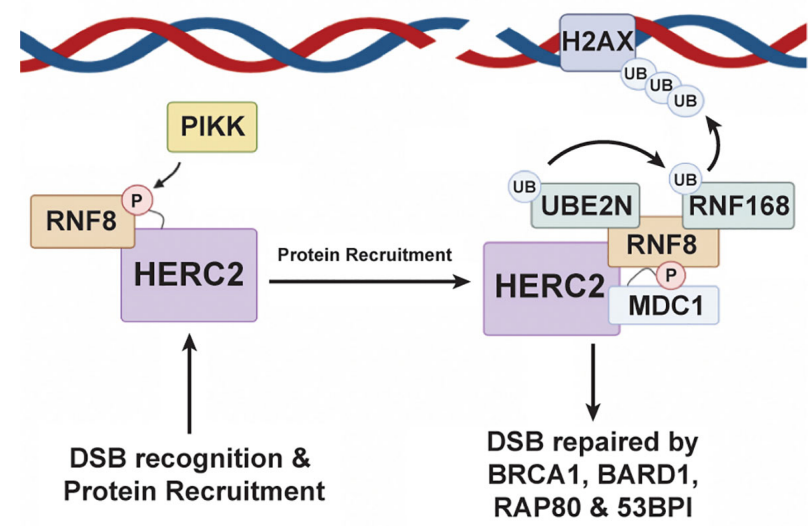

FIGURE 4 | HERC2 serves as a scaffold to facilitate H2A ubiquitylation in response to DNA double strand breaks. HERC2 initiates the repair response for DSBs by using its catalytic HECT domain as a binding scaffold for RING finger protein 8 (RNF8), a RING E3 ubiquitin ligase, to bring RNF8 into close proximity to a site of DNA damage. After binding RNF8 to its HECT domain, HERC2 coordinates the formation of a complex between UBE2N (aka Ubc13), an E2 ubiquitin conjugating enzyme, and RNF168 to catalyze the attachment of K63-polyubiquitin chains onto histones at the site of damaged DNA. This HERC2-mediated K63-polyubiquitylation activity then signals for the recruitment of healing factors like breast cancer gene 1 (BRCA1), receptor associate protein 80 (RAP80), and 53BP1 to elicit an effective DDR response. This figure was created with BioRender.com. factor 53BP1, all of which are required to carry out the full DDR response $(176,182,183)$.

Recent studies indicate that HERC2 continues to play a role in the DSB repair pathway after the recruitment of these DNA repair factors. For example, it is suggested that HERC2 uses its phosphorylated $C$-terminal tail to help stabilize BRCA1, BARD1, and RAP80 by binding onto their degrons sites during the G2-M phase transition of cell replication thereby protecting these DDR proteins from proteasomal degradation while they carry out their DNA repair activities (176). This HERC2-dependent activity is critical to the prevention of cellular oncogenesis by acting to screen and repair the cell's genetic material at potentially carcinogenic mutation sites that were overlooked during Sphase DNA replication.

Collectively, studies on the onco-suppressive activities of HERC2 suggest it as a promising drug target for future immunotherapeutic treatments, particularly in cases of breast cancer development and pathogenesis. While HERC2 has been extensively characterized in a biochemical context, the mechanistic and structural basis for the involvement of HERC2 in the NEURL4-p53-MDM2 mediated DSB and DDR pathways remain largely unexplored. Intriguingly, in both pathways HERC2 serves as a scaffold that recruits and orchestrates the timely activities of regulatory proteins that are key to regulating p53-MDM2 intracellular concentration and/or DNA integrity. It is conceivable that HERC2 targeted drug development needs to be focused on enhancing the onco-suppressive activities of HERC2 to control the progression of cancer. As a prerequisite to developing these treatments, it will be paramount that structural studies be conducted to learn how HERC2 uses its different protein-protein interaction domains, including its catalytic HECT domain, to carry out specific molecular mechanisms that regulate p53 activity and the DDR response. For example, there are many unanswered questions on how the $\mathrm{N}$-terminal variable domains of HERC2 contribute to substrate recognition and HERC2-dependent ubiquitylation. The mechanisms used by HERC2 in DNA maintenance/repair and p53-MDM2 modulation in the cell are also unknown. Additionally, studies on the role of conformationally flexible in the acidic $C$-terminal tail of HERC2 for building polyubiquitin chains during DDR and p53 oligomerization and clarifying how HERC2 recognizes and targets proteins to the p53 promoter region to regulate $\mathrm{p} 53$-related gene expression and/or a damaged DNA site to facilitate DNA repair are needed. Expanded studies on HERC2 could prove to be pivotal in the development of new immunotherapeutic treatments that target specific HECT E3 protein-protein interactions in the cell to elicit a specific intracellular immunological response against cancers.

\section{HECT E3 UBIQUITIN LIGASES AS CANCER DRUG TARGETS-MOVING FORWARD}

Recent advances in the biochemical and structural characterization of HECT E3 ubiquitin ligases have revealed 
these enzymes are critical regulators of the p53-MDM2 and DDR pathways. To date, only one HECT E3 ubiquitin ligase specific cancer drug, Bortezomib, has been reported to effectively modulate the activity of the NEDD4L and HERC subfamily ligases discussed in this review (184). Intriguingly, a recent 2019 study used phage library analysis to identify a class of bicyclic peptides that demonstrate a general inhibitory effect on the HECT E3 ligases ITCH, WWP1, SMURF1 and HECW1 by competitively binding to the $\mathrm{E} 2$ interaction site on the $\mathrm{N}$-lobe of the HECT domain (185). However, the activity of these small molecule competitive inhibitors provided no specific anticancer effects when tested in tumorigenic cell lines (185). Perhaps one of the largest obstacles for developing HECT specific anticancer therapeutics is the diversity of mechanisms and structures associated within each HECT subfamily and the reality that many of these mechanisms, structures, and their functional roles in cancer pathogenesis remain largely unknown. Concurrently, the amount of knowledge that remains to be uncovered on the NEDD4L subgroup, as well as other members of the broader HECT family, provide many opportunities for the generation of novel therapeutics to treat a broad range of cancers. As new discoveries continue to be made on this fascinating group of proteins, our knowledge into the scope of molecular mechanisms, protein-protein interactions, and identified substrates engaged by HECT E3 ubiquitin ligases in oncogenesis will continue to expand.

It will become increasingly important that new structural and biophysical studies be conducted on members of the HECT E3 ubiquitin ligases to clarify how the HECT domain architecture contributes to HECT catalytic dysfunction in p53 and related cellular pathways. For example, further examination of the mechanisms used by SMURF1 to catalyze MDM2/MDMX heterodimerization and increase the MDM2-dependent ubiquitylation of p53 could allow for the synthesis of small

\section{REFERENCES}

1. Harashima H, Dissmeyer N, Schnittger A. Cell cycle control across the eukaryotic kingdom. Trends Cell Biol (2013) 23:345-56. doi: 10.1016/ j.tcb.2013.03.002

2. Lacerda R, Menezes J, Candeias MM. Alternative Mechanisms of mRNA Translation Initiation in Cellular Stress Response and Cancer. Adv Exp Med Biol (2019) 1157:117-32. doi: 10.1007/978-3-030-19966-1_6

3. MacMillan CD, Leong HS, Dales DW, Robertson AE, Lewis JD, Chambers AF, et al. andStage of breast cancer progression influences cellular response to activation of the WNT/planar cell polarity pathway. Sci Rep (2014) 4:6315. doi: 10.1038/srep06315

4. Palmieri D, Scarpa M, Tessari A, Uka R, Amari F, Lee C, et al. Ran Binding Protein 9 (RanBP9) is a novel mediator of cellular DNA damage response in lung cancer cells. Oncotarget (2016) 7:18371-83. doi: 10.18632/ oncotarget.7813

5. Raulf N, El-Attar R, Kulms D, Lecis D, Delia D, Walczak H, et al. Differential response of head and neck cancer cell lines to TRAIL or Smac mimetics is associated with the cellular levels and activity of caspase- 8 and caspase- 10 . Br J Cancer (2014) 111:1955-64. doi: 10.1038/bjc.2014.521

6. Savina NV, Nikitchenko NV, Kuzhir TD, Rolevich AI, Krasny SA, Goncharova RI. The Cellular Response to Oxidatively Induced DNA Damage and Polymorphism of Some DNA Repair Genes Associated with Clinicopathological Features of Bladder Cancer. Oxid Med Cell Longev (2016) 2016:5710403. doi: 10.1155/2016/5710403 molecule inhibitors drugs that block MDMX-SMURF1 complex formation. Likewise, the development of therapies that promote the upregulation of p53 pro-apoptotic cellular signaling in SMURF1 overexpressed cells to disrupt tumor growth is another avenue that needs to be studied. An improved molecular understanding of how HERC2 uses its multidomain structure to direct the ATM and ATR-dependent phosphorylation of p53 and MDM2 will be pivotal to uncovering the HERC2-dependent mechanisms involved with p53-MDM2 regulation. Expanded studies on HECW1 and WWP1 will also be critical in the development of small molecule therapeutics to target these enzymes and their roles in p53 regulation. With so little known about the diverse structural, molecular, and mechanistic bases used by HECT E3 ligases to regulate the p53-MDM2, DDR, and other pathways implicated in oncogenesis, now is an exciting time to be researching this class of enzymes that are at the nexus for the development of new onco-therapeutic treatments.

\section{AUTHOR CONTRIBUTIONS}

Conceptualization, NM, RL, and DS. Writing-original draft preparation, review and editing, and revisions, NM, RL, and DS. Figures, NM, RL, and DS. Supervision, DS. All authors contributed to the article and approved the submitted version.

\section{FUNDING}

This research was supported by the National Institutes of Health, R15GM126432 (DS). NM was the recipient of an Arthur E. Martell and Thomas T. Sugihara Summer Undergraduate Scholarship from Clark University.

7. Sulli G, Di Micco R, d'Adda di Fagagna F. Crosstalk between chromatin state and DNA damage response in cellular senescence and cancer. Nat Rev Cancer (2012) 12:709-20. doi: 10.1038/nrc3344

8. Watanabe T, Morinaga S, Akaike M, Numata M, Tamagawa H, Yamamoto N, et al. The cellular level of histone $\mathrm{H} 3$ lysine 4 dimethylation correlates with response to adjuvant gemcitabine in Japanese pancreatic cancer patients treated with surgery. Eur J Surg Oncol (2012) 38:1051-7. doi: 10.1016/ j.ejso.2012.08.008

9. Zhang K, Zhang B, Bai Y, Dai L. E2F1 promotes cancer cell sensitivity to cisplatin by regulating the cellular DNA damage response through miR-26b in esophageal squamous cell carcinoma. J Cancer (2020) 11:301-10. doi: $10.7150 /$ jca. 33983

10. Timofeev O, Koch L, Niederau C, Tscherne A, Schneikert J, Klimovich M, et al. Phosphorylation Control of p53 DNA-Binding Cooperativity Balances Tumorigenesis and Aging. Cancer Res (2020) 80:5231-44. doi: 10.1158/ 0008-5472.CAN-20-2002

11. Kim JH, Yoon EK, Chung HJ, Park SY, Hong KM, Lee CH, et al. p53 acetylation enhances Taxol-induced apoptosis in human cancer cells. Apoptosis (2013) 18:110-20. doi: 10.1007/s10495-012-0772-8

12. Fei Q, Shang K, Zhang J, Chuai S, Kong D, Zhou T, et al. Histone methyltransferase SETDB1 regulates liver cancer cell growth through methylation of p53. Nat Commun (2015) 6:8651. doi: 10.1038/ncomms9651

13. Ashikari D, Takayama K, Tanaka T, Suzuki Y, Obinata D, Fujimura T, et al Androgen induces G3BP2 and SUMO-mediated p53 nuclear export in prostate cancer. Oncogene (2017) 36:6272-81. doi: 10.1038/onc.2017.225 
14. Shaw P, Freeman J, Bovey R, Iggo R. Regulation of specific DNA binding by p53: evidence for a role for O-glycosylation and charged residues at the carboxy-terminus. Oncogene (1996) 12:921-30.

15. Appella E, Anderson CW. Post-translational modifications and activation of p53 by genotoxic stresses. Eur J Biochem (2001) 268:2764-72. doi: 10.1046/ j.1432-1327.2001.02225.x

16. Di Ventura B, Funaya C, Antony C, Knop M, Serrano L. Reconstitution of $\mathrm{Mdm} 2$-dependent post-translational modifications of p53 in yeast. PloS One (2008) 3:e1507. doi: 10.1371/journal.pone.0001507

17. Saito S, Yamaguchi H, Higashimoto Y, Chao C, Xu Y, Fornace AJJr., et al. Phosphorylation site interdependence of human p53 post-translational modifications in response to stress. J Biol Chem (2003) 278:37536-44. doi: 10.1074/jbc.M305135200

18. Taira N, Yoshida K. Post-translational modifications of p53 tumor suppressor: determinants of its functional targets. Histol Histopathol (2012) 27:437-43. doi: 10.14670/HH-27.437

19. Tanaka T. Regulation of p53 function and promoter selectivity by posttranslational modifications. Seikagaku (2010) 82:200-9.

20. Xu Y. Regulation of $\mathrm{p} 53$ responses by post-translational modifications. Cell Death Differ (2003) 10:400-3. doi: 10.1038/sj.cdd.4401182

21. Masuda Y, Saeki Y, Arai N, Kawai H, Kukimoto I, Tanaka K, et al. Stepwise multipolyubiquitination of p53 by the E6AP-E6 ubiquitin ligase complex. J Biol Chem (2019) 294:14860-75. doi: 10.1074/jbc.RA119.008374

22. Meng J, Tagalakis AD, Hart SL. Silencing E3 Ubiqutin ligase ITCH as a potential therapy to enhance chemotherapy efficacy in p53 mutant neuroblastoma cells. Sci Rep (2020) 10:1046. doi: 10.1038/s41598-02057854-6

23. Michnov O, Solomayer E, Fehm T, Stubenrauch F, Iftner T. Knock down of p53 or its ubiquitin ligase E6AP does not affect the sensitivity of human papillomavirus-positive cervical cancer cells to cisplatin. Am J Cancer Res (2012) 2:309-21.

24. Rolfe M, Beer-Romero P, Glass S, Eckstein J, Berdo I, Theodoras A, et al. Reconstitution of $\mathrm{p} 53$-ubiquitinylation reactions from purified components: the role of human ubiquitin-conjugating enzyme UBC4 and E6-associated protein (E6AP). Proc Natl Acad Sci USA (1995) 92:3264-8. doi: 10.1073/ pnas.92.8.3264

25. Beaudenon S, Huibregtse JM. HPV E6, E6AP and cervical cancer. BMC Biochem (2008) 9 Suppl 1:S4. doi: 10.1186/1471-2091-9-S1-S4

26. Gamell C, Bandilovska I, Gulati T, Kogan A, Lim SC, Kovacevic Z, et al. E6AP Promotes a Metastatic Phenotype in Prostate Cancer. iScience (2019) 22:1-15. doi: 10.1016/j.isci.2019.10.065

27. Gamell C, Gulati T, Levav-Cohen Y, Young RJ, Do H, Pilling P, et al. Reduced abundance of the E3 ubiquitin ligase E6AP contributes to decreased expression of the INK4/ARF locus in non-small cell lung cancer. Sci Signal (2017) 461:eaaf8223. doi: 10.1126/scisignal.aaf8223

28. Mani A, Oh AS, Bowden ET, Lahusen T, Lorick KL, Weissman AM, et al. E6AP mediates regulated proteasomal degradation of the nuclear receptor coactivator amplified in breast cancer 1 in immortalized cells. Cancer Res (2006) 66:8680-6. doi: 10.1158/0008-5472.CAN-06-0557

29. Owais A, Mishra RK, Kiyokawa H. The HECT E3 Ligase E6AP/UBE3A as a Therapeutic Target in Cancer and Neurological Disorders. Cancers (Basel) (2020) 12:2108. doi: 10.3390/cancers12082108

30. Raghu D, Paul PJ, Gulati T, Deb S, Khoo C, Russo A, et al. E6AP promotes prostate cancer by reducing p27 expression. Oncotarget (2017) 8:42939-48. doi: 10.18632/oncotarget.17224

31. Chen C, Sun X, Guo P, Dong XY, Sethi P, Zhou W, et al. Ubiquitin E3 ligase WWP1 as an oncogenic factor in human prostate cancer. Oncogene (2007) 26:2386-94. doi: 10.1038/sj.onc.1210021

32. Sakashita $\mathrm{H}$, Inoue $\mathrm{H}$, Akamine $\mathrm{S}$, Ishida $\mathrm{T}$, Inase $\mathrm{N}$, Shirao $\mathrm{K}$, et al. Identification of the NEDD4L gene as a prognostic marker by integrated microarray analysis of copy number and gene expression profiling in nonsmall cell lung cancer. Ann Surg Oncol (2013) 20 Suppl 3:S590-8. doi: 10.1245/s10434-013-3059-6

33. Li H, Xiao N, Wang Y, Wang R, Chen Y, Pan W, et al. Smurf1 regulates lung cancer cell growth and migration through interaction with and ubiquitination of PIPKIgamma. Oncogene (2017) 36:5668-80. doi: 10.1038/onc.2017.166
34. Bonanno L, Costa C, Majem M, Sanchez JJ, Rodriguez I, Gimenez-Capitan A, et al. Combinatory effect of BRCA1 and HERC2 expression on outcome in advanced non-small-cell lung cancer. BMC Cancer (2016) 16:312. doi: 10.1186/s12885-016-2339-5

35. Chen JJ, Zhang W. High expression of WWP1 predicts poor prognosis and associates with tumor progression in human colorectal cancer. Am J Cancer Res (2018) 8:256-65.

36. Qi H, Grenier J, Fournier A, Labrie C. Androgens differentially regulate the expression of NEDD4L transcripts in LNCaP human prostate cancer cells. Mol Cell Endocrinol (2003) 210:51-62. doi: 10.1016/j.mce.2003.08.009

37. Tanksley JP, Chen X, Coffey RJ. NEDD4L is downregulated in colorectal cancer and inhibits canonical WNT signaling. PloS One (2013) 8:e81514. doi: 10.1371/journal.pone.0081514

38. Yang H, Zhu J, Wang G, Liu H, Zhou Y, Qian J. STK35 Is Ubiquitinated by NEDD4L and Promotes Glycolysis and Inhibits Apoptosis Through Regulating the AKT Signaling Pathway, Influencing Chemoresistance of Colorectal Cancer. Front Cell Dev Biol (2020) 8:582695. doi: 10.3389/ fcell. 2020.582695

39. Chen C, Zhou Z, Ross JS, Zhou W, Dong JT. The amplified WWP1 gene is a potential molecular target in breast cancer. Int J Cancer (2007) 121:80-7. doi: $10.1002 / \mathrm{ijc} .22653$

40. Yu L, Liu X, Cui K, Di Y, Xin L, Sun X, et al. SND1 Acts Downstream of TGFbetal and Upstream of Smurfl to Promote Breast Cancer Metastasis. Cancer Res (2015) 75:1275-86. doi: 10.1158/0008-5472.CAN-14-2387

41. Bian S. miR-4319 inhibited the development of thyroid cancer by modulating FUS-stabilized SMURF1. J Cell Biochem (2020) 121:174-82. doi: $10.1002 /$ jcb. 29026

42. Tao Y, Sun C, Zhang T, Song Y. SMURF1 promotes the proliferation, migration and invasion of gastric cancer cells. Oncol Rep (2017) 38:1806-14. doi: 10.3892/or.2017.5825

43. Zhang Y, Wang W, Cai S, Chen Y, Wang Q, Pan Q, et al. Reciprocal regulation between betaTrCP and Smurf1 suppresses proliferative capacity of liver cancer cells. J Cell Physiol (2017) 232:3347-59. doi: 10.1002/ jcp. 25780

44. Lin JH, Hsieh SC, Chen JN, Tsai MH, Chang CC. WWP1 gene is a potential molecular target of human oral cancer. Oral Surg Oral Med Oral Pathol Oral Radiol (2013) 116:221-31. doi: 10.1016/j.oooo.2013.05.006

45. Yang Q, Zhao J, Cui M, Gi S, Wang W, Han X. Nedd4L expression is decreased in ovarian epithelial cancer tissues compared to ovarian noncancer tissue. J Obstet Gynaecol Res (2015) 41:1959-64. doi: 10.1111/ jog. 12808

46. Chen X, Chen S, Li Y, Gao Y, Huang S, Li H, et al. SMURF1-mediated ubiquitination of ARHGAP26 promotes ovarian cancer cell invasion and migration. Exp Mol Med (2019) 51:1-12. doi: 10.1038/s12276-019-0236-0

47. Hershko A, Ciechanover A. The ubiquitin system. Annu Rev Biochem (1998) 67:425-79. doi: 10.1146/annurev.biochem.67.1.425

48. Komander D. The emerging complexity of protein ubiquitination. Biochem Soc Trans (2009) 37:937-53. doi: 10.1042/BST0370937

49. Komander D, Rape M. The ubiquitin code. Annu Rev Biochem (2012) 81:203-29. doi: 10.1146/annurev-biochem-060310-170328

50. Yu F, Wang S, Zhang W, Tang J, Wang H, Yu L, et al. Genome-wide identification of genes encoding putative secreted E3 ubiquitin ligases and functional characterization of PbRING1 in the biotrophic protist Plasmodiophora brassicae. Curr Genet (2019) 65:1355-65. doi: 10.1007/ s00294-019-00989-5

51. Goto Y, Koyasu S, Kobayashi M, Harada H. The emerging roles of the ubiquitination/deubiquitination system in tumor radioresistance regarding DNA damage responses, cell cycle regulation, hypoxic responses, and antioxidant properties: Insight into the development of novel radiosensitizing strategies. Mutat Res (2017) 803-805:76-81. doi: 10.1016/ j.mrfmmm.2017.07.007

52. Ditzel M, Meier P. Ubiquitylation in apoptosis: DIAPl's (N-)en(d)igma. Cell Death Differ (2005) 12:1208-12. doi: 10.1038/sj.cdd.4401711

53. Gomez-Martin D, Diaz-Zamudio M, Alcocer-Varela J. Ubiquitination system and autoimmunity: the bridge towards the modulation of the immune response. Autoimmun Rev (2008) 7:284-90. doi: 10.1016/ j.autrev.2007.11.026 
54. Smith VL, Jackson L, Schorey JS. Ubiquitination as a Mechanism To Transport Soluble Mycobacterial and Eukaryotic Proteins to Exosomes. J Immunol (2015) 195:2722-30. doi: 10.4049/jimmunol.1403186

55. Abbas T. The Role of Ubiquitination and SUMOylation in DNA Replication. Curr Issues Mol Biol (2020) 40:189-220. doi: 10.21775/cimb.040.189

56. Pickart CM. Mechanisms underlying ubiquitination. Annu Rev Biochem (2001) 70:503-33. doi: 10.1146/annurev.biochem.70.1.503

57. Pickart CM, Eddins MJ. Ubiquitin: structures, functions, mechanisms. Biochim Biophys Acta (2004) 1695:55-72. doi: 10.1016/j.bbamcr.2004.09.019

58. Capili AD, Lima CD. Taking it step by step: mechanistic insights from structural studies of ubiquitin/ubiquitin-like protein modification pathways. Curr Opin Struct Biol (2007) 17:726-35. doi: 10.1016/j.sbi.2007.08.018

59. Breslow E, Chauhan Y, Daniel R, Tate S. Role of methionine-1 in ubiquitin conformation and activity. Biochem Biophys Res Commun (1986) 138:43744. doi: 10.1016/0006-291X(86)90300-1

60. Mihalik B, Gaborik Z, Varnai P, Clark AJ, Catt KJ, Hunyady L. Endocytosis of the AT1A angiotensin receptor is independent of ubiquitylation of its cytoplasmic serine/threonine-rich region. Int J Biochem Cell Biol (2003) 35:992-1002. doi: 10.1016/S1357-2725(02)00277-7

61. Amodio G, Margarucci L, Moltedo O, Casapullo A, Remondelli P. Identification of Cysteine Ubiquitylation Sites on the Sec23A Protein of the COPII Complex Required for Vesicle Formation from the ER. Open Biochem J (2017) 11:36-46. doi: 10.2174/1874091X01711010036

62. Deshaies RJ, Joazeiro CA. RING domain E3 ubiquitin ligases. Annu Rev Biochem (2009) 78:399-434. doi: 10.1146/annurev.biochem.78.101807.093809

63. Hatakeyama S, Nakayama KI. U-box proteins as a new family of ubiquitin ligases. Biochem Biophys Res Commun (2003) 302:635-45. doi: 10.1016/ S0006-291X(03)00245-6

64. Spratt DE, Walden H, Shaw GS. RBR E3 ubiquitin ligases: new structures, new insights, new questions. Biochem J (2014) 458:421-37. doi: 10.1042/BJ20140006

65. Kraft E, Stone SL, Ma L, Su N, Gao Y, Lau OS, et al. Genome analysis and functional characterization of the E2 and RING-type E3 ligase ubiquitination enzymes of Arabidopsis. Plant Physiol (2005) 139:1597611. doi: 10.1104/pp.105.067983

66. Metzger MB, Hristova VA, Weissman AM. HECT and RING finger families of E3 ubiquitin ligases at a glance. J Cell Sci (2012) 125:531-7. doi: 10.1242/ jcs.091777

67. Marin I. RBR ubiquitin ligases: Diversification and streamlining in animal lineages. J Mol Evol (2009) 69:54-64. doi: 10.1007/s00239-009-9252-3

68. Marin I. Diversification and Specialization of Plant RBR Ubiquitin Ligases. PloS One (2010) 5:e11579. doi: 10.1371/journal.pone.0011579

69. Marin I, Lucas JI, Gradilla AC, Ferrus A. Parkin and relatives: the RBR family of ubiquitin ligases. Physiol Genomics (2004) 17:253-63. doi: 10.1152/ physiolgenomics.00226.2003

70. Wang Y, Argiles-Castillo D, Kane EI, Zhou A, Spratt DE. HECT E3 ubiquitin ligases - emerging insights into their biological roles and disease relevance. J Cell Sci (2020) 133:jcs228072. doi: 10.1242/jcs.228072

71. Scheffner M, Nuber U, Huibregtse JM. Protein ubiquitination involving an E1-E2-E3 enzyme ubiquitin thioester cascade. Nature (1995) 373:81-3. doi: $10.1038 / 373081 \mathrm{a} 0$

72. Huang L, Kinnucan E, Wang G, Beaudenon S, Howley PM, Huibregtse JM, et al. Structure of an E6AP-UbcH7 complex: insights into ubiquitination by the E2-E3 enzyme cascade. Science (1999) 286:1321-6. doi: 10.1126/ science.286.5443.1321

73. Kee Y, Huibregtse JM. Regulation of catalytic activities of HECT ubiquitin ligases. Biochem Biophys Res Commun (2007) 354:329-33. doi: 10.1016/ j.bbrc.2007.01.025

74. Lorenz S. Structural mechanisms of HECT-type ubiquitin ligases. Biol Chem (2018) 399:127-45. doi: 10.1515/hsz-2017-0184

75. Laine A, Ronai Z. Regulation of p53 localization and transcription by the HECT domain E3 ligase WWP1. Oncogene (2007) 26:1477-83. doi: 10.1038/ sj.onc. 1209924

76. David D, Nair SA, Pillai MR. Smurf E3 ubiquitin ligases at the cross roads of oncogenesis and tumor suppression. Biochim Biophys Acta (2013) 1835:11928. doi: 10.1016/j.bbcan.2012.11.003

77. Li Y, Ozaki T, Kikuchi H, Yamamoto H, Ohira M, Nakagawara A. A novel HECT-type E3 ubiquitin protein ligase NEDL1 enhances the p53-mediated apoptotic cell death in its catalytic activity-independent manner. Oncogene (2008) 27:3700-9. doi: 10.1038/sj.onc.1211032

78. Nie J, Xie P, Liu L, Xing G, Chang Z, Yin Y, et al. Smad ubiquitylation regulatory factor $1 / 2($ Smurf1/2) promotes $\mathrm{p} 53$ degradation by stabilizing the E3 ligase MDM2. J Biol Chem (2010) 285:22818-30. doi: 10.1074/ jbc.M110.126920

79. Huibregtse JM, Scheffner M, Beaudenon S, Howley PM. A family of proteins structurally and functionally related to the E6-AP ubiquitin-protein ligase. Proc Natl Acad Sci USA (1995) 920:2563-7. doi: 10.1073/pnas.92.7.2563

80. Schwarz SE, Rosa JL, Scheffner M. Characterization of human hect domain family members and their interaction with $\mathrm{UbcH} 5$ and UbcH7. J Biol Chem (1998) 273:12148-54. doi: 10.1074/jbc.273.20.12148

81. Berndsen CE, Wolberger C. New insights into ubiquitin E3 ligase mechanism. Nat Struct Mol Biol (2014) 21:301-7. doi: 10.1038/nsmb.2780

82. Zheng N, Shabek N. Ubiquitin Ligases: Structure, Function, and Regulation. Annu Rev Biochem (2017) 86:129-57. doi: 10.1146/annurev-biochem060815-014922

83. Rotin D, Kumar S. Physiological functions of the HECT family of ubiquitin ligases. Nat Rev Mol Cell Biol (2009) 10:398-409. doi: 10.1038/nrm2690

84. Plant PJ, Yeger H, Staub O, Howard P, Rotin D. The C2 domain of the ubiquitin protein ligase Nedd4 mediates Ca2+-dependent plasma membrane localization. J Biol Chem (1997) 272:32329-36. doi: 10.1074/jbc.272.51. 32329

85. Staub O, Dho S, Henry P, Correa J, Ishikawa T, McGlade J, et al. WW domains of Nedd 4 bind to the proline-rich PY motifs in the epithelial $\mathrm{Na}+$ channel deleted in Liddle's syndrome. EMBO J (1996) 15:2371-80. doi: 10.1002/j.1460-2075.1996.tb00593.x

86. Spagnol G, Kieken F, Kopanic JL, Li H, Zach S, Stauch KL, et al. Structural Studies of the Nedd4 WW Domains and Their Selectivity for the Connexin43 (Cx43) Carboxyl Terminus. J Biol Chem (2016) 291:7637-50. doi: 10.1074/jbc.M115.701417

87. Kanelis V, Bruce MC, Skrynnikov NR, Rotin D, Forman-Kay JD. Structural determinants for high-affinity binding in a Nedd4 WW3* domain-Comm PY motif complex. Structure (2006) 14:543-53. doi: 10.1016/ j.str.2005.11.018

88. Jennings MD, Blankley RT, Baron M, Golovanov AP, Avis JM. Specificity and autoregulation of Notch binding by tandem WW domains in suppressor of Deltex. J Biol Chem (2007) 282:29032-42. doi: 10.1074/jbc.M703453200

89. Maspero E, Mari S, Valentini E, Musacchio A, Fish A, Pasqualato S, et al. Structure of the HECT:ubiquitin complex and its role in ubiquitin chain elongation. EMBO Rep (2011) 12:342-9. doi: 10.1038/embor.2011.21

90. Aragon E, Goerner N, Xi Q, Gomes T, Gao S, Massague J, et al. Structural basis for the versatile interactions of Smad7 with regulator WW domains in TGF-beta Pathways. Structure (2012) 20:1726-36. doi: 10.1016/ j.str.2012.07.014

91. Aragon E, Goerner N, Zaromytidou AI, Xi Q, Escobedo A, Massague J, et al. A Smad action turnover switch operated by WW domain readers of a phosphoserine code. Genes Dev (2011) 25:1275-88. doi: 10.1101/gad. 2060811

92. Zhang W, Wu KP, Sartori MA, Kamadurai HB, Ordureau A, Jiang C, et al. System-Wide Modulation of HECT E3 Ligases with Selective Ubiquitin Variant Probes. Mol Cell (2016) 62:121-36. doi: 10.1016/j.molcel.2016. 02.005

93. Desrochers G, Cappadocia L, Lussier-Price M, Ton AT, Ayoubi R, Serohijos A, et al. Molecular basis of interactions between SH3 domain-containing proteins and the proline-rich region of the ubiquitin ligase Itch. J Biol Chem (2017) 292:6325-38. doi: 10.1074/jbc.M116.754440

94. Liu Y, Lau J, Li W, Tempel W, Li L, Dong A, et al. Structural basis for the regulatory role of the PPxY motifs in the thioredoxin-interacting protein TXNIP. Biochem J (2016) 473:179-87. doi: 10.1042/BJ20150830

95. Wang Z, Liu Z, Chen X, Li J, Yao W, Huang S, et al. A multi-lock inhibitory mechanism for fine-tuning enzyme activities of the HECT family E3 ligases. Nat Commun (2019) 10:3162. doi: 10.1038/s41467-019-11224-7

96. Wahl LC, Watt JE, Yim HTT, De Bourcier D, Tolchard J, Soond SM, et al. Smad7 Binds Differently to Individual and Tandem WW3 and WW4 Domains of WWP2 Ubiquitin Ligase Isoforms. Int J Mol Sci (2019) 20:4682. doi: 10.3390/ijms20194682 
97. Wiesner S, Ogunjimi AA, Wang HR, Rotin D, Sicheri F, Wrana JL, et al. Autoinhibition of the HECT-type ubiquitin ligase Smurf2 through its C2 domain. Cell (2007) 130:651-62. doi: 10.1016/j.cell.2007.06.050

98. Chong PA, Lin H, Wrana JL, Forman-Kay JD. Coupling of tandem Smad ubiquitination regulatory factor (Smurf) WW domains modulates target specificity. Proc Natl Acad Sci USA (2010) 107:18404-9. doi: 10.1073/ pnas. 1003023107

99. Ogunjimi AA, Briant DJ, Pece-Barbara N, Le Roy C, Di Guglielmo GM, Kavsak P, et al. Regulation of Smurf2 ubiquitin ligase activity by anchoring the E2 to the HECT domain. Mol Cell (2005) 19:297-308. doi: 10.1016/ j.molcel.2005.06.028

100. Liu J, Xue Z, Zhang Y, Vann KR, Shi X, Kutateladze TG. Structural Insight into Binding of the ZZ Domain of HERC2 to Histone H3 and SUMO1. Structure (2020) 28:1225-30.e3. doi: 10.1016/j.str.2020.07.003

101. Dasso M. RCC1 in the cell cycle: the regulator of chromosome condensation takes on new roles. Trends Biochem Sci (1993) 18:96-101. doi: 10.1016/09680004(93)90161-F

102. Ohtsubo M, Okazaki H, Nishimoto T. The RCC1 protein, a regulator for the onset of chromosome condensation locates in the nucleus and binds to DNA. J Cell Biol (1989) 109:1389-97. doi: 10.1083/jcb.109.4.1389

103. Laity JH, Lee BM, Wright PE. Zinc finger proteins: new insights into structural and functional diversity. Curr Opin Struct Biol (2001) 11:39-46. doi: 10.1016/S0959-440X(00)00167-6

104. Kaustov L, Lukin J, Lemak A, Duan S, Ho M, Doherty R, et al. The conserved $\mathrm{CPH}$ domains of Cul7 and PARC are protein-protein interaction modules that bind the tetramerization domain of p53. J Biol Chem (2007) 282:113007. doi: 10.1074/jbc.M611297200

105. Cubillos-Rojas M, Amair-Pinedo F, Peiro-Jordan R, Bartrons R, Ventura F, Rosa JL. The E3 ubiquitin protein ligase HERC2 modulates the activity of tumor protein p53 by regulating its oligomerization. J Biol Chem (2014) 289:14782-95. doi: 10.1074/jbc.M113.527978

106. Elahian F, Sepehrizadeh Z, Moghimi B, Mirzaei SA. Human cytochrome b5 reductase: structure, function, and potential applications. Crit Rev Biotechnol (2014) 34:134-43. doi: 10.3109/07388551.2012.732031

107. McMillan BJ, Schnute B, Ohlenhard N, Zimmerman B, Miles L, Beglova N, et al. A tail of two sites: a bipartite mechanism for recognition of notch ligands by mind bomb E3 ligases. Mol Cell (2015) 57:912-24. doi: 10.1016/ j.molcel.2015.01.019

108. Grossberger R, Gieffers C, Zachariae W, Podtelejnikov AV, Schleiffer A, Nasmyth K, et al. Characterization of the DOC1/APC10 subunit of the yeast and the human anaphase-promoting complex. J Biol Chem (1999) 274:14500-7. doi: 10.1074/jbc.274.20.14500

109. Alarcon R, Koumenis C, Geyer RK, Maki CG, Giaccia AJ. Hypoxia induces p53 accumulation through MDM2 down-regulation and inhibition of E6mediated degradation. Cancer Res (1999) 59:6046-51.

110. Ansari T, Brimer N, Vande Pol SB. Peptide interactions stabilize and restructure human papillomavirus type $16 \mathrm{E} 6$ to interact with p53. J Virol (2012) 86:11386-91. doi: 10.1128/JVI.01236-12

111. Gewin L, Galloway DA. E box-dependent activation of telomerase by human papillomavirus type $16 \mathrm{E} 6$ does not require induction of c-myc. J Virol (2001) 75:7198-201. doi: 10.1128/JVI.75.15.7198-7201.2001

112. Beaudenon S, Dastur A, Huibregtse JM. Expression and assay of HECT domain ligases. Methods Enzymol (2005) 398:112-25. doi: 10.1016/S00766879(05)98011-7

113. Huibregtse JM, Scheffner M, Howley PM. Cloning and expression of the cDNA for E6-AP, a protein that mediates the interaction of the human papillomavirus E6 oncoprotein with p53. Mol Cell Biol (1993) 13:775-84. doi: 10.1128/MCB.13.2.775

114. Kao WH, Beaudenon SL, Talis AL, Huibregtse JM, Howley PM. Human papillomavirus type 16 E6 induces self-ubiquitination of the E6AP ubiquitinprotein ligase. J Virol (2000) 74:6408-17. doi: 10.1128/JVI.74.14.6408-6417.2000

115. Martinez-Noel G, Luck K, Kuhnle S, Desbuleux A, Szajner P, Galligan JT, et al. Network Analysis of UBE3A/E6AP-Associated Proteins Provides Connections to Several Distinct Cellular Processes. J Mol Biol (2018) 430:1024-50. doi: 10.1016/j.jmb.2018.01.021

116. Huibregtse JM, Scheffner M, Howley PM. A cellular protein mediates association of p53 with the E6 oncoprotein of human papillomavirus types
16 or 18. $E M B O J$ (1991) 10:4129-35. doi: 10.1002/j.1460-2075. 1991.tb04990.x

117. Martinez-Zapien D, Ruiz FX, Poirson J, Mitschler A, Ramirez J, Forster A, et al. Structure of the E6/E6AP/p53 complex required for HPV-mediated degradation of p53. Nature (2016) 529:541-5. doi: 10.1038/nature16481

118. Nuber U, Schwarz SE, Scheffner M. The ubiquitin-protein ligase E6associated protein (E6-AP) serves as its own substrate. Eur J Biochem (1998) 254:643-9. doi: 10.1046/j.1432-1327.1998.2540643.x

119. Ro HS, Koh BH, Jung SO, Park HK, Shin YB, Kim MG, et al. Surface plasmon resonance imaging protein arrays for analysis of triple protein interactions of HPV, E6, E6AP, and p53. Proteomics (2006) 6:2108-11. doi: 10.1002/ pmic. 200500635

120. Sailer C, Offensperger F, Julier A, Kammer KM, Walker-Gray R, Gold MG, et al. Structural dynamics of the E6AP/UBE3A-E6-p53 enzyme-substrate complex. Nat Commun (2018) 9:4441. doi: 10.1038/s41467-018-06953-0

121. Scheffner M, Huibregtse JM, Howley PM. Identification of a human ubiquitin-conjugating enzyme that mediates the E6-AP-dependent ubiquitination of p53. Proc Natl Acad Sci USA (1994) 91:8797-801. doi: 10.1073/pnas.91.19.8797

122. Scheffner M, Huibregtse JM, Vierstra RD, Howley PM. The HPV-16 E6 and E6-AP complex functions as a ubiquitin-protein ligase in the ubiquitination of p53. Cell (1993) 75:495-505. doi: 10.1016/0092-8674(93)90384-3

123. Stutz C, Reinz E, Honegger A, Bulkescher J, Schweizer J, Zanier K, et al. Intracellular Analysis of the Interaction between the Human Papillomavirus Type 16 E6 Oncoprotein and Inhibitory Peptides. PloS One (2015) 10: e0132339. doi: 10.1371/journal.pone.0132339

124. Nakagawa S, Huibregtse JM. Human scribble (Vartul) is targeted for ubiquitin-mediated degradation by the high-risk papillomavirus E6 proteins and the E6AP ubiquitin-protein ligase. Mol Cell Biol (2000) 20:8244-53. doi: 10.1128/MCB.20.21.8244-8253.2000

125. Talis AL, Huibregtse JM, Howley PM. The role of E6AP in the regulation of p53 protein levels in human papillomavirus (HPV)-positive and HPVnegative cells. J Biol Chem (1998) 273:6439-45. doi: 10.1074/jbc.273.11.6439

126. Thatte J, Banks L. Human Papillomavirus 16 (HPV-16), HPV-18, and HPV31 E6 Override the Normal Phosphoregulation of E6AP Enzymatic Activity. J Virol (2017) 91. doi: 10.1128/JVI.01390-17

127. White EA, Kramer RE, Tan MJ, Hayes SD, Harper JW, Howley PM. Comprehensive analysis of host cellular interactions with human papillomavirus E6 proteins identifies new E6 binding partners and reflects viral diversity. J Virol (2012) 86:13174-86. doi: 10.1128/JVI.02172-12

128. Huibregtse JM, Scheffner M, Howley PM. Localization of the E6-AP regions that direct human papillomavirus E6 binding, association with p53, and ubiquitination of associated proteins. Mol Cell Biol (1993) 13:4918-27. doi: 10.1128/MCB.13.8.4918

129. Kuhnle S, Martinez-Noel G, Leclere F, Hayes SD, Harper JW, Howley PM. Angelman syndrome-associated point mutations in the $\mathrm{Zn}(2+)$-binding $\mathrm{N}$ terminal (AZUL) domain of UBE3A ubiquitin ligase inhibit binding to the proteasome. J Biol Chem (2018) 293:18387-99. doi: 10.1074/jbc. RA118.004653

130. Cooper B, Schneider S, Bohl J, Jiang Y, Beaudet A, Vande Pol S. Requirement of E6AP and the features of human papillomavirus E6 necessary to support degradation of p53. Virology (2003) 306:87-99. doi: 10.1016/S0042-6822(02) 00012-0

131. Peschiaroli A, Scialpi F, Bernassola F, El Sherbini el S, Melino G. The E3 ubiquitin ligase WWP1 regulates DeltaNp63-dependent transcription through Lys63 linkages. Biochem Biophys Res Commun (2010) 402:425-30. doi: $10.1016 /$ j.bbrc.2010.10.050

132. Bellomaria A, Barbato G, Melino G, Paci M, Melino S. Recognition of p63 by the E3 ligase ITCH: Effect of an ectodermal dysplasia mutant. Cell Cycle (2010) 9:3730-9. doi: 10.4161/cc.9.18.12933

133. Bellomaria A, Barbato G, Melino G, Paci M, Melino S. Recognition mechanism of p63 by the E3 ligase Itch: novel strategy in the study and inhibition of this interaction. Cell Cycle (2012) 11:3638-48. doi: 10.4161/ cc. 21918

134. Melino S, Bellomaria A, Nepravishta R, Paci M, Melino G. p63 threonine phosphorylation signals the interaction with the WW domain of the E3 ligase Itch. Cell Cycle (2014) 13:3207-17. doi: 10.4161/15384101.2014.951285 
135. Rossi M, Aqeilan RI, Neale M, Candi E, Salomoni P, Knight RA, et al. The E3 ubiquitin ligase Itch controls the protein stability of p63. Proc Natl Acad Sci USA (2006) 103:12753-8. doi: 10.1073/pnas.0603449103

136. Rossi M, De Simone M, Pollice A, Santoro R, La Mantia G, Guerrini L, et al. Itch/AIP4 associates with and promotes p63 protein degradation. Cell Cycle (2006) 5:1816-22. doi: 10.4161/cc.5.16.2861

137. Bakkers J, Camacho-Carvajal M, Nowak M, Kramer C, Danger B, Hammerschmidt M. Destabilization of DeltaNp63alpha by Nedd4mediated ubiquitination and Ubc9-mediated sumoylation, and its implications on dorsoventral patterning of the zebrafish embryo. Cell Cycle (2005) 4:790-800. doi: 10.4161/cc.4.6.1694

138. Miyazaki K, Ozaki T, Kato C, Hanamoto T, Fujita T, Irino S, et al. A novel HECT-type E3 ubiquitin ligase, NEDL2, stabilizes p73 and enhances its transcriptional activity. Biochem Biophys Res Commun (2003) 308:106-13. doi: 10.1016/S0006-291X(03)01347-0

139. Rossi M, De Laurenzi V, Munarriz E, Green DR, Liu YC, Vousden KH, et al. The ubiquitin-protein ligase Itch regulates p73 stability. EMBO J (2005) 24:836-48. doi: 10.1038/sj.emboj.7600444

140. Gao K, An J, Zhang Y, Jin X, Ma J, Peng J, et al. The E3 ubiquitin ligase Itch and Yap1 have antagonistic roles in the regulation of ASPP2 protein stability. FEBS Lett (2015) 589:94-101. doi: 10.1016/j.febslet.2014.11.030

141. Gen Y, Yasui K, Kitaichi T, Iwai N, Terasaki K, Dohi O, et al. ASPP2 suppresses invasion and TGF-betal-induced epithelial-mesenchymal transition by inhibiting Smad7 degradation mediated by E3 ubiquitin ligase ITCH in gastric cancer. Cancer Lett (2017) 398:52-61. doi: 10.1016/ j.canlet.2017.04.002

142. Louria-Hayon I, Alsheich-Bartok O, Levav-Cohen Y, Silberman I, Berger M, Grossman T, et al. E6AP promotes the degradation of the PML tumor suppressor. Cell Death Differ (2009) 16:1156-66. doi: 10.1038/cdd.2009.31

143. Xu C, Fan CD, Wang X. Regulation of Mdm2 protein stability and the $\mathrm{p} 53$ response by NEDD4-1 E3 ligase. Oncogene (2015) 34:281-9. doi: 10.1038/ onc. 2013.557

144. Wu W, Sato K, Koike A, Nishikawa H, Koizumi H, Venkitaraman AR, et al. HERC2 is an E3 ligase that targets BRCA1 for degradation. Cancer Res (2010) 70:6384-92. doi: 10.1158/0008-5472.CAN-10-1304

145. Holloway A, Simmonds M, Azad A, Fox JL, Storey A. Resistance to UVinduced apoptosis by beta-HPV5 E6 involves targeting of activated BAK for proteolysis by recruitment of the HERC1 ubiquitin ligase. Int J Cancer (2015) 136:2831-43. doi: 10.1002/ijc.29350

146. Ho KC, Zhou Z, She YM, Chun A, Cyr TD, Yang X. Itch E3 ubiquitin ligase regulates large tumor suppressor 1 stability [corrected]. Proc Natl Acad Sci USA (2011) 108:4870-5. doi: 10.1073/pnas.1101273108

147. Salah Z, Melino G, Aqeilan RI. Negative regulation of the Hippo pathway by E3 ubiquitin ligase ITCH is sufficient to promote tumorigenicity. Cancer Res (2011) 71:2010-20. doi: 10.1158/0008-5472.CAN-10-3516

148. Chang L, Shen L, Zhou H, Gao J, Pan H, Zheng L, et al. ITCH nuclear translocation and H1.2 polyubiquitination negatively regulate the DNA damage response. Nucleic Acids Res (2019) 47:824-42. doi: 10.1093/nar/ gky1199

149. Shinada K, Tsukiyama T, Sho T, Okumura F, Asaka M, Hatakeyama S. RNF43 interacts with NEDL1 and regulates p53-mediated transcription. Biochem Biophys Res Commun (2011) 404:143-7. doi: 10.1016/ j.bbrc.2010.11.082

150. Garcia-Cano J, Sanchez-Tena S, Sala-Gaston J, Figueras A, Vinals F, Bartrons $\mathrm{R}$, et al. Regulation of the MDM2-p53 pathway by the ubiquitin ligase HERC2. Mol Oncol (2020) 14:69-86. doi: 10.1002/1878-0261.12592

151. Bekker-Jensen S, Mailand N. Assembly and function of DNA double-strand break repair foci in mammalian cells. DNA Repair (Amst) (2010) 9:1219-28. doi: 10.1016/j.dnarep.2010.09.010

152. Nguyen Huu NS, Ryder WD, Zeps N, Flasza M, Chiu M, Hanby AM, et al. Tumour-promoting activity of altered WWP1 expression in breast cancer and its utility as a prognostic indicator. J Pathol (2008) 216:93-102. doi: 10.1002/path.2385

153. Jones DC, Wein MN, Oukka M, Hofstaetter JG, Glimcher MJ, Glimcher LH. Regulation of adult bone mass by the zinc finger adapter protein Schnurri-3. Science (2006) 312:1223-7. doi: 10.1126/science.1126313

154. Shu L, Zhang H, Boyce BF, Xing L. Ubiquitin E3 ligase Wwp1 negatively regulates osteoblast function by inhibiting osteoblast differentiation and migration. J Bone mineral Res Off J Am Soc Bone Mineral Res (2013) 28:1925-35. doi: 10.1002/jbmr.1938

155. Azmi P, Seth A. RNF11 is a multifunctional modulator of growth factor receptor signalling and transcriptional regulation. Eur J Cancer (2005) 41:2549-60. doi: 10.1016/j.ejca.2005.08.020

156. Chen C, Zhou Z, Liu R, Li Y, Azmi PB, Seth AK. The WW domain containing E3 ubiquitin protein ligase 1 upregulates ErbB2 and EGFR through RING finger protein 11. Oncogene (2008) 27:6845-55. doi: 10.1038/onc.2008.288

157. Yeung B, Ho KC, Yang X. WWP1 E3 ligase targets LATS1 for ubiquitinmediated degradation in breast cancer cells. PloS One (2013) 8:e61027. doi: 10.1371/journal.pone.0061027

158. Marine JC, Lozano G. Mdm2-mediated ubiquitylation: p53 and beyond. Cell Death Differ (2010) 17:93-102. doi: 10.1038/cdd.2009.68

159. Wu Z, Zan P, Li S, Liu J, Wang J, Chen D, et al. Knockdown of WWP1 inhibits growth and invasion, but induces apoptosis of osteosarcoma cells. Int J Clin Exp Pathol (2015) 8:7869-77.

160. Zhou Z, Liu R, Chen C. The WWP1 ubiquitin E3 ligase increases TRAIL resistance in breast cancer. Int J Cancer (2012) 130:1504-10. doi: 10.1002/ ijc. 26122

161. Komuro A, Imamura T, Saitoh M, Yoshida Y, Yamori T, Miyazono K, et al. Negative regulation of transforming growth factor-beta (TGF-beta) signaling by WW domain-containing protein 1 (WWP1). Oncogene (2004) 23:691423. doi: $10.1038 /$ sj.onc. 1207885

162. Ebisawa T, Fukuchi M, Murakami G, Chiba T, Tanaka K, Imamura T, et al. Smurf1 interacts with transforming growth factor-beta type I receptor through Smad7 and induces receptor degradation. J Biol Chem (2001) 276:12477-80. doi: 10.1074/jbc.C100008200

163. Suzuki C, Murakami G, Fukuchi M, Shimanuki T, Shikauchi Y, Imamura T, et al. Smurf1 regulates the inhibitory activity of Smad7 by targeting Smad7 to the plasma membrane. J Biol Chem (2002) 277:39919-25. doi: 10.1074/ jbc.M201901200

164. Tajima Y, Goto K, Yoshida M, Shinomiya K, Sekimoto T, Yoneda Y, et al. Chromosomal region maintenance 1 (CRM1)-dependent nuclear export of Smad ubiquitin regulatory factor 1 (Smurf1) is essential for negative regulation of transforming growth factor-beta signaling by Smad7. J Biol Chem (2003) 278:10716-21. doi: 10.1074/jbc.M212663200

165. Yamaguchi T, Kurisaki A, Yamakawa N, Minakuchi K, Sugino H. FKBP12 functions as an adaptor of the Smad7-Smurfl complex on activin type I receptor. J Mol Endocrinol (2006) 36:569-79. doi: 10.1677/jme.1.01966

166. Xia Q, Zhang H, Zhang P, Li Y, Xu M, Li X, et al. Oncogenic Smurf1 promotes PTEN wild-type glioblastoma growth by mediating PTEN ubiquitylation. Oncogene (2020) 39:5902-15. doi: 10.1038/s41388-020-01400-1

167. Meulmeester E, Frenk R, Stad R, de Graaf P, Marine JC, Vousden KH, et al. Critical role for a central part of $\mathrm{Mdm} 2$ in the ubiquitylation of $\mathrm{p} 53 . \mathrm{Mol}$ Cell Biol (2003) 23:4929-38. doi: 10.1128/MCB.23.14.4929-4938.2003

168. Saito A, Hayashi T, Okuno S, Nishi T, Chan PH. Modulation of p53 degradation via MDM2-mediated ubiquitylation and the ubiquitinproteasome system during reperfusion after stroke: role of oxidative stress. J Cereb Blood Flow Metab (2005) 25:267-80. doi: 10.1038/sj.jcbfm.9600028

169. Boyer L, Turchi L, Desnues B, Doye A, Ponzio G, Mege JL, et al. CNF1induced ubiquitylation and proteasome destruction of activated RhoA is impaired in Smurf1-/- cells. Mol Biol Cell (2006) 17:2489-97. doi: 10.1091/ mbc.e05-09-0876

170. Guo R, Yamashita M, Zhang Q, Zhou Q, Chen D, Reynolds DG, et al. Ubiquitin ligase Smurf1 mediates tumor necrosis factor-induced systemic bone loss by promoting proteasomal degradation of bone morphogenetic signaling proteins. J Biol Chem (2008) 283:23084-92. doi: 10.1074/ jbc.M709848200

171. Li S, Lu K, Wang J, An L, Yang G, Chen H, et al. Ubiquitin ligase Smurf1 targets TRAF family proteins for ubiquitination and degradation. Mol Cell Biochem (2010) 338:11-7. doi: 10.1007/s11010-009-0315-y

172. Gajjar M, Candeias MM, Malbert-Colas L, Mazars A, Fujita J, Olivares-Illana $\mathrm{V}$, et al. The p53 mRNA-Mdm2 interaction controls Mdm2 nuclear trafficking and is required for p53 activation following DNA damage. Cancer Cell (2012) 21:25-35. doi: 10.1016/j.ccr.2011.11.016

173. Weber AM, Ryan AJ. ATM and ATR as therapeutic targets in cancer. Pharmacol Ther (2015) 149:124-38. doi: 10.1016/j.pharmthera.2014.12.001 
174. Kang TH, Lindsey-Boltz LA, Reardon JT, Sancar A. Circadian control of XPA and excision repair of cisplatin-DNA damage by cryptochrome and HERC2 ubiquitin ligase. Proc Natl Acad Sci USA (2010) 107:4890-5. doi: 10.1073/pnas.0915085107

175. Izawa N, Wu W, Sato K, Nishikawa H, Kato A, Boku N, et al. HERC2 Interacts with Claspin and regulates DNA origin firing and replication fork progression. Cancer Res (2011) 71:5621-5. doi: 10.1158/0008-5472.CAN-11-0385

176. Bekker-Jensen S, Rendtlew Danielsen J, Fugger K, Gromova I, Nerstedt A, Lukas C, et al. HERC2 coordinates ubiquitin-dependent assembly of DNA repair factors on damaged chromosomes. Nat Cell Biol (2010) 12:80-6; sup pp 1-12. doi: $10.1038 /$ ncb2008

177. Zhu M, Zhao H, Liao J, Xu X. HERC2/USP20 coordinates CHK1 activation by modulating CLASPIN stability. Nucleic Acids Res (2014) 42:13074-81. doi: 10.1093/nar/gku978

178. Yuan J, Luo K, Deng M, Li Y, Yin P, Gao B, et al. HERC2-USP20 axis regulates DNA damage checkpoint through Claspin. Nucleic Acids Res (2014) 42:13110-21. doi: 10.1093/nar/gku1034

179. Kuhnle S, Kogel U, Glockzin S, Marquardt A, Ciechanover A, Matentzoglu $\mathrm{K}$, et al. Physical and functional interaction of the HECT ubiquitin-protein ligases E6AP and HERC2. J Biol Chem (2011) 286:19410-6. doi: 10.1074/ jbc.M110.205211

180. Valnegri P, Huang J, Yamada T, Yang Y, Mejia LA, Cho HY, et al. RNF8/ UBC13 ubiquitin signaling suppresses synapse formation in the mammalian brain. Nat Commun (2017) 8:1271. doi: 10.1038/s41467-017-01333-6

181. Oestergaard VH, Pentzold C, Pedersen RT, Iosif S, Alpi A, Bekker-Jensen S, et al. RNF8 and RNF168 but not HERC2 are required for DNA damage- induced ubiquitylation in chicken DT40 cells. DNA Repair (Amst) (2012) 11:892-905. doi: 10.1016/j.dnarep.2012.08.005

182. Wu W, Rokutanda N, Takeuchi J, Lai Y, Maruyama R, Togashi Y, et al. HERC2 Facilitates BLM and WRN Helicase Complex Interaction with RPA to Suppress G-Quadruplex DNA. Cancer Res (2018) 78:6371-85. doi: 10.1158/0008-5472.CAN-18-1877

183. Vissers JH, van Lohuizen M, Citterio E. The emerging role of Polycomb repressors in the response to DNA damage. J Cell Sci (2012) 125:3939-48. doi: $10.1242 /$ jcs. 107375

184. Wang Z, Wang J, Li X, Xing L, Ding Y, Shi P, et al. Bortezomib prevents oncogenesis and bone metastasis of prostate cancer by inhibiting WWP1, Smurf1 and Smurf2. Int J Oncol (2014) 45:1469-78. doi: 10.3892/ ijo.2014.2545

185. Weber J, Polo S, Maspero E. HECT E3 Ligases: A Tale With Multiple Facets. Front Physiol (2019) 10:370. doi: 10.3389/fphys.2019.00370

Conflict of Interest: The authors declare that the research was conducted in the absence of any commercial or financial relationships that could be construed as a potential conflict of interest.

Copyright (c) 2021 Mathieu, Levin and Spratt. This is an open-access article distributed under the terms of the Creative Commons Attribution License (CC BY). The use, distribution or reproduction in other forums is permitted, provided the original author(s) and the copyright owner(s) are credited and that the original publication in this journal is cited, in accordance with accepted academic practice. No use, distribution or reproduction is permitted which does not comply with these terms. 